\title{
ATDC is required for the initiation of KRAS-induced pancreatic tumorigenesis
}

\author{
Lidong Wang, ${ }^{1,2}$ Huibin Yang, ${ }^{3}$ Andrea Zamperone, ${ }^{1,2}$ Daniel Diolaiti, ${ }^{1,2}$ Phillip L. Palmbos, ${ }^{4}$ \\ Ethan V. Abel, ${ }^{5}$ Vinee Purohit, ${ }^{1,2}$ Igor Dolgalev, ${ }^{2}$ Andrew D. Rhim, ${ }^{6}$ Mats Ljungman, ${ }^{3}$ \\ Christina H. Hadju, ${ }^{7}$ Christopher J. Halbrook, ${ }^{5}$ Dafna Bar-Sagi, ${ }^{2,8,9}$ Marina Pasca di Magliano, ${ }^{10,11}$ \\ Howard C. Crawford, ${ }^{4,5}$ and Diane M. Simeone ${ }^{1,2,7}$ \\ ${ }^{1}$ Department of Surgery, New York University School of Medicine, New York, New York 10016, USA; ${ }^{2}$ Perlmutter Cancer Center, \\ NYU Langone Medical Center, New York University, New York, New York 10016, USA; ${ }^{3}$ Department of Radiation Oncology, \\ ${ }^{4}$ Department of Internal Medicine, ${ }^{5}$ Department of Molecular and Integrative Physiology, University of Michigan, Ann Arbor, \\ Michigan 48109, USA; ${ }^{6}$ Department of Gastroenterology, Hepatology, and Nutrition, University of Texas MD Anderson Cancer \\ Center, Houston, Texas 77030, USA; ${ }^{7}$ Department of Pathology, ${ }^{8}$ Department of Biochemistry and Molecular Pharmacology, \\ ${ }^{9}$ Department of Medicine, New York University School of Medicine, New York, New York 10016, USA; ${ }^{10}$ Department of Surgery, \\ ${ }^{11}$ Department of Cell and Developmental Biology, University of Michigan, Ann Arbor, Michigan 48109, USA
}

Pancreatic adenocarcinoma (PDA) is an aggressive disease driven by oncogenic KRAS and characterized by late diagnosis and therapeutic resistance. Here we show that deletion of the ataxia-telangiectasia group D-complementing $(A t d c)$ gene, whose human homolog is up-regulated in the majority of pancreatic adenocarcinoma, completely prevents PDA development in the context of oncogenic KRAS. ATDC is required for KRAS-driven acinar-ductal metaplasia (ADM) and its progression to pancreatic intraepithelial neoplasia (PanIN). As a result, mice lacking ATDC are protected from developing PDA. Mechanistically, we show ATDC promotes ADM progression to PanIN through activation of $\beta$-catenin signaling and subsequent SOX9 up-regulation. These results provide new insight into PDA initiation and reveal ATDC as a potential target for preventing early tumor-initiating events.

[Keywords: pancreatic ductal adenocarcinoma; KRAS; acinar-to-ductal metaplasia; PanIN lesion; ATDC; TRIM29; SOX9; $\beta$-catenin]

Supplemental material is available for this article.

Received December 5, 2018; revised version accepted April 8, 2019.

Pancreatic ductal adenocarcinoma (PDA) is a lethal human malignancy that is typically diagnosed at an advanced stage and is largely unresponsive to chemotherapy and ionizing radiation. With a 5 -yr survival rate of $9 \%$, PDA displays the worst prognosis of any major malignancy and is predicted to become the second leading cause of cancer-related death by 2030 (Rahib et al. 2014). A better understanding of key signaling mechanisms driving initiation and progression of PDA may lead to both early diagnosis and intervention.

The earliest steps of pancreatic tumorigenesis involve transdifferentiation of acinar cells to a metaplastic ductlike phenotype in a process known as acinar-ductal metaplasia (ADM) (Zhu et al. 2007). Lineage tracing studies in genetically engineered mice (GEMs) show that ADM results from direct transdifferentiation of adult acinar cells to a ductal cell phenotype upon KRAS ${ }^{\mathrm{G} 12 \mathrm{D}}$ expression (De La et al. 2008; Habbe et al. 2008). ADM is transiently observed in response to damage, such as pancreatitis;

Corresponding author: diane.simeone@nyulangone.org Article published online ahead of print. Article and publication date are online at http://www.genesdev.org/cgi/doi/10.1101/gad.323303.118. however, in the presence of oncogenic KRAS, ADM is sustained and progresses to pancreatic intraepithelial neoplasia (PanIN) lesions, which ultimately may give rise to PDA (Guerra et al. 2007).

Interestingly, oncogenic KRAS ${ }^{\mathrm{G} 12 \mathrm{D}}$ expression in acinar cells is insufficient by itself to induce ADM. In a GEM model where the vast majority of acinar cells express $\mathrm{KRAS}^{\mathrm{G12D}}$, only a small cohort of cells gives rise to ADM/PanIN following a latency period (Hingorani et al. 2003). In humans, secondary events-either genetic changes such as acquisition of loss-of-function mutations in TP53, SMAD4, and CDKN2A or environmental factors such as tissue damage/inflammation-are required, along with KRAS mutations, for ADM/PanIN progression (The Cancer Genome Atlas Research Network 2017). Additionally, ADM is facilitated by the loss of acinar-specific transcription factors such as PTF1A and MIST1 (Pin et al. 2001;

(C) 2019 Wang et al. This article is distributed exclusively by Cold Spring Harbor Laboratory Press for the first six months after the full-issue publication date (see http://genesdev.cshlp.org/site/misc/terms.xhtml). After six months, it is available under a Creative Commons License (Attribution-NonCommercial 4.0 International), as described at http://creativecommons.org/licenses/by-nc/4.0/. 
Krah et al. 2015) and, conversely, is promoted by expression of ductal genes such as SOX9 (Kopp et al. 2012).

The ataxia-telangiectasia (AT) group D-complementing $(A T D C)$ gene was first identified in the hunt for the gene responsible for the genetic disorder AT (Kapp et al. 1992) but later was shown not to be involved in AT. ATDC, also termed tripartite motif protein 29 (TRIM29), belongs to the TRIM protein family and contains the characteristic B1-B2-CC TRIM motifs but lacks the RING finger domain (Reymond et al. 2001). ATDC is normally expressed in several tissues such as the lungs, prostate, colon, and alveolar macrophages but is undetectable in the heart, brain, pancreas, and small intestine (Hosoi and Kapp 1994). Several studies have demonstrated elevated expression of ATDC in multiple cancer types (Hatakeyama 2016), and this has been associated with poor prognosis and decreased overall survival (Lai et al. 2013; Harris et al. 2015). We demonstrated previously that ATDC is expressed in the majority of human PDA (Wang et al. 2009), where ATDC serves as an invasive switch by activating $\beta$-catenin signaling and up-regulating CD44, resulting in epithelial-mesenchymal transition (EMT) and leading to PanIN progression to PDA (Wang et al. 2009, 2015). In this study, we examined whether ATDC is required for KRAS-driven tumorigenesis and how ATDC regulates oncogenic KRAS-induced initiation of ADM, progression to PanIN, and, eventually, PDA development.

\section{Results}

\section{Genetic ablation of ATDC does not affect pancreas development and morphology}

We generated an Atdc-floxed strain (Supplemental Fig. S1A) and bred Atdc-floxed mice with Pdx1-Cre transgenic mice (Supplemental Fig. S1B) to determine whether the lack of Atdc affected pancreatic development or function. In Pdx1-Cre transgenic mice, CRE recombinase expression is targeted to the epithelial lineages of the pancreas (Hingorani et al. 2003). Consistent with lack of ATDC expression in the normal pancreas, both Pdx1-Cre; Atdc ${ }^{f 1 /+}$ $\left(\mathrm{CA}^{-/+}\right)$and Pdx1-Cre; Atdc $c^{f l / f 1}\left(\mathrm{CA}^{-/-}\right)$mice were born at the expected frequency and showed normal pancreatic weight, morphology, and histology throughout postnatal life, up to 12 mo of age ( $n=25$ animals each group) (Supplemental Fig. S1C,D).

\section{Generation of Pdx1-Cre; Kras ${ }^{\text {LSL-G12D/+ }}$; Trp53 ${ }^{\mathrm{fl} /+}$;

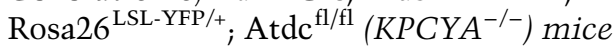

To explore the role of ATDC signaling in an autochthonous mouse model of PDA, we crossed $A t d c^{f 1 / f 1}$ mice with a Pdx1-Cre; Kras ${ }^{L S L-G 12 D /+} ; \quad \operatorname{Trp53} 3^{f l+} ; \quad$ Rosa26 $6^{L S L-Y F P /+}$ (KPCY) model (Fig. 1A; Rhim et al. 2012). Because Pdx1Cre mediates recombination exclusively in the epithelial cells of the pancreas, this combination of alleles results in the simultaneous activation of mutant Kras, deletion of Atdc, and loss of one Trp53 allele within this tissue compartment. $\mathrm{KPCYA}^{-/-}$mice were born at expected Mendelian ratios and were phenotypically normal at birth. Using a variety of approaches, we confirmed that ATDC was efficiently deleted in the pancreas of $\mathrm{KPCYA}^{-/-}$(Fig. $1 \mathrm{~B}, \mathrm{C}$; Supplemental Fig. S1E), that mutant KRAS ${ }^{\mathrm{G} 12 \mathrm{D}}$ and YFP were expressed, and that Trp53 expression was lowered by $50 \%$ in both of KPCY and $\mathrm{KPCYA}^{-/-}$mice (Fig. 1D,E; Supplemental Fig. S1F,G).

\section{ATDC is required for KRAS ${ }^{G 12 D}$-induced PanIN progression and $P D A$ formation}

The KPCY mouse model of pancreatic cancer displays all of the stages of tumorigenesis-from PanIN lesions to
A

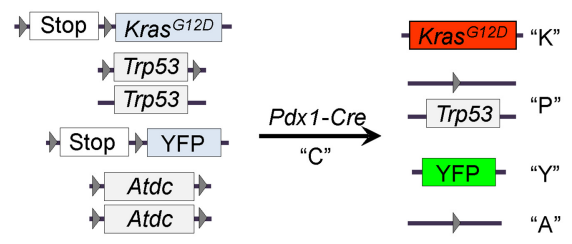

C

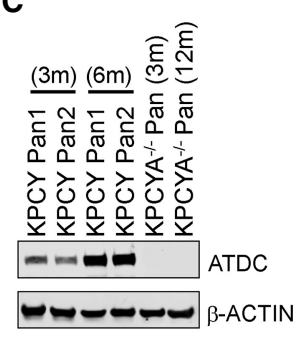

D

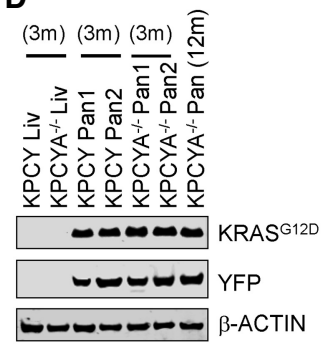

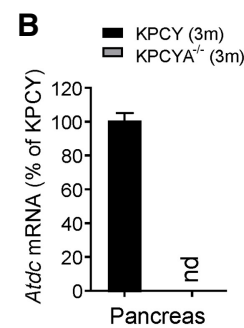

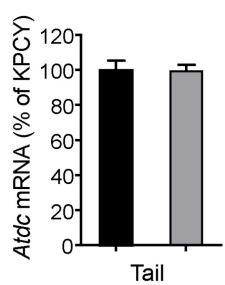

E

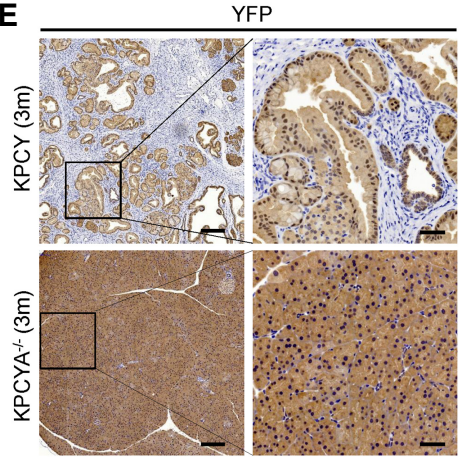

Figure 1. Conditional knockout of pancreas-specific ATDC expression in KPCY mice. (A) Schematic of the KPCYA ${ }^{-/-}$mouse model, which uses the Kras ${ }^{L S L-G 12 D /+}(" \mathrm{~K}$ "), Pdx1Cre ("C $\left.\mathrm{C}^{\prime \prime}\right), \operatorname{Trp} 53^{f 1 /+}\left({ }^{\prime \prime} \mathrm{P}^{\prime \prime}\right)$, Rosa ${ }^{\mathrm{YFP} /+}\left(" \mathrm{Y}^{\prime \prime}\right)$, and $A t d c^{f 1 / f 1}\left(" \mathrm{~A}^{\prime \prime}\right)$ mice. (B) Quantitative RT-PCR (qRT-PCR) analysis of Atdc mRNA expression in the pancreata or tails of 3-moold KPCY and $\mathrm{KPCYA}^{-/-}$mice. $n=5$ per group. (nd) Not detectable. (C) Western blot analysis of ATDC expression in pancreata (Pan) from 3-, 6-, or 12-mo-old KPCY and $\mathrm{KPCYA}^{-/-}$mice. $(D)$ Western blot analysis of KRAS ${ }^{\mathrm{G} 12 \mathrm{D}}$ and YFP expression in pancreata (Pan) or livers (Liv) from 3- and 12mo-old KPCY and KPCYA ${ }^{-/-}$mice. $(E)$ Representative immunohistochemical images of YFP expression in pancreatic sections from 3-mo-old KPCY or $\mathrm{KPCYA}^{-/-}$mice. Scale bar, $200 \mu \mathrm{m}$. The right panels are magnified views. Scale bar, $50 \mu \mathrm{m}$. (m) Months. 
metastatic PDA-found in human patients (Rhim et al. 2012). Examination of pancreata of 3-mo-old KPCY mice (12 out of 12 [100\%]) exhibited abundant ADM and lowand high-grade PanIN lesions, with an average of 19.8 ADM and PanIN lesions per field (Fig. 2A-D). In contrast, the entire pancreata of 3-mo-old $\mathrm{KPCYA}^{-1-}$ mice were normal in 11 of $15(73.3 \%)$ mice (Fig. 2A-D). In the remaining four of $15(26.7 \%) \mathrm{KPCYA}^{-/-}$mice, ADM and low-grade PanIN1 lesions were observed rarely, with an average of five ADM/PanIN1 lesions per field (Fig. 2AD). Importantly, we found that all of the ADM and PanIN1 lesions in the $\mathrm{KPCYA}^{-/-}$mice expressed ATDC due to incomplete recombination of the floxed Atdc alleles (Supplemental Fig. S2A). Similar results were obtained in $\mathrm{KPCYA}^{-/-}$mice sacrificed at 12 mo of age, which exhibited completely normal pancreata (nine of 12 [75\%] $\mathrm{KPCYA}^{-/-}$mice) and rare ADM or PanIN1 lesions (three of the 12 [25\%] $\mathrm{KPCYA}^{-1-}$ mice), respectively (Fig. 2A$\mathrm{D})$. In distinct contrast, all pancreata of 7-mo-old KPCY mice were replaced by aggressive PDA with lung and liver metastasis (Fig. 2E,F).

Histological analysis of the pancreata from KPCY and $\mathrm{KPCYA}^{-/-}$mice showed that inactivation of Atdc blocked the formation of Alcian blue-positive PanIN lesions in 3 -mo-old $\mathrm{KPCYA}^{-/-}$mice versus age- and sex-matched KPCY mice (Supplemental Fig. S2B,C). Additional immunohistochemical staining to assess expression of Ki67, cleaved caspase 3 (CC3), p-ERK-1/2, and $\alpha$-smooth muscle actin ( $\alpha$-SMA) in pancreatic sections from 3-mo-old KPCY and $\mathrm{KPCYA}^{-1-}$ mice showed that Atdc knockout inhibited proliferation and ERK-1/2 phosphorylation and decreased the apoptotic rate and desmoplastic response (SMA expression) typically seen during PanIN formation (Supplemental Fig. S2D-J).

To determine whether ATDC had a dose-dependent effect on pancreatic tumorigenesis, we examined the phenotype of mice heterozygous for the Atdc locus $\left(\mathrm{KPCYA}^{+/-}\right)$ (Supplemental Fig. S2K). Both initiation and progression

A
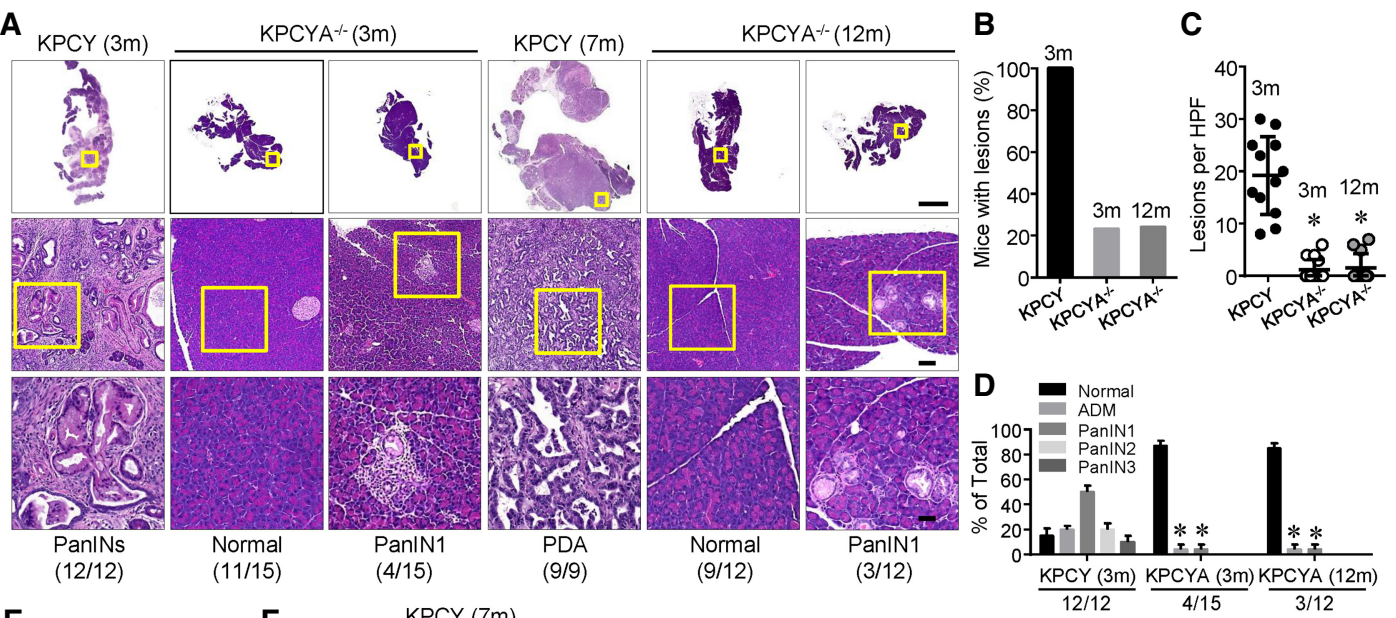

E
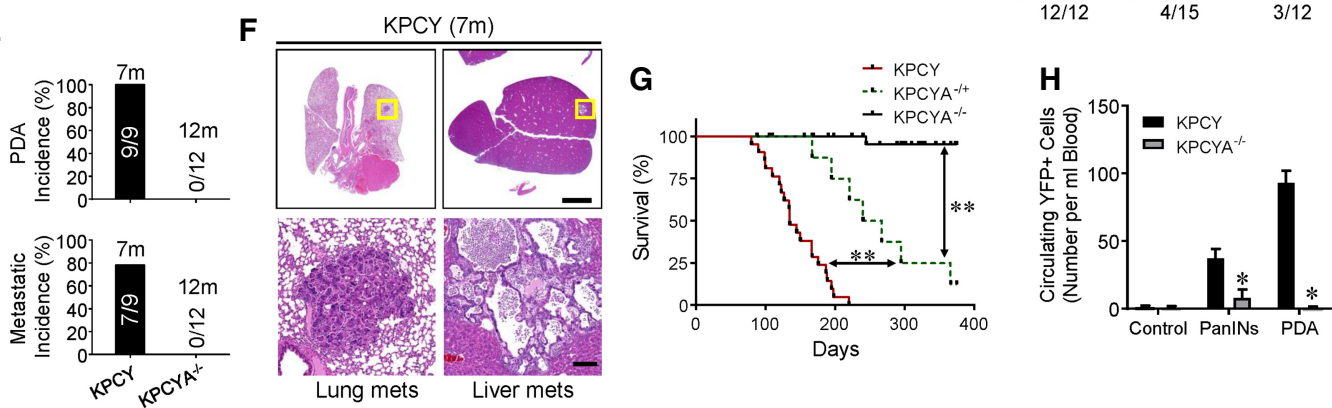

Figure 2. ATDC is required for KRAS $\mathrm{G}^{\mathrm{G} 12 \mathrm{D}}$-induced PanIN progression and PDA formation. $(A$, top panels $)$ Representative H\&E images of whole pancreata from 3- or 7-mo-old KPCY and 3- or 12-mo-old KPCYA ${ }^{-1-}$ mice. Scale bar, $5000 \mu \mathrm{m}$. The bottom panels (scale bar, $50 \mu \mathrm{m}$ ) are magnified views of staining patterns from the middle panels (yellow box) (scale bar, $100 \mu \mathrm{m}) .(B)$ The percentage of mice harboring $\mathrm{ADM} /$ PanIN lesions in 3-mo-old KPCY mice and 3- or 12-mo-old KPCYA ${ }^{-/-}$micee. $(\mathrm{m})$ Months. $(C)$ The number of ADM/PanIN lesions per 200× optical high-power field (HPF) (four random 200 × fields per representative slide) for each 3-mo-old KPCY mouse ( $n=12$ ) and 3- or 12-mo-old KPCYA ${ }^{-/-}$mouse $(n=4)$. ( $\left.^{*}\right) P<0.05$ versus KPCY. $(D)$ Quantification of the proportion of the pancreas occupied by ADM/ PanIN lesions in KPCY mice (12 of 12) at 3 mo of age and $\mathrm{KPCYA}^{-/-}$mice at 3 mo of age (four of 15) or 12 mo of age (three of 12). Data are shown as mean $\pm \mathrm{SE}$. $\left({ }^{*}\right) P<0.01$. (E) Quantification of primary tumor (top panel) or metastatic incidence (bottom panel) in 7mo-old KPCY and 3- or 12-mo-old KPCYA ${ }^{-1-}$ mice. $(F)$ Representative H\&E-stained sections display lung and liver metastasis in 7-moold KPCY mice. (m) Months. Scale bar, $2000 \mu \mathrm{m}$; inset scale bar, $100 \mu \mathrm{m}$. (G) Kaplan-Meier survival curves of KPCY, KPCYA ${ }^{-/+}$, and $\mathrm{KPCYA}^{-/-}$mice. $\left(^{* *}\right) P<0.01$ between KPCY, $\mathrm{KPCYA}^{-/+}$, and $\mathrm{KPCYA}^{-1-}$ mice. $(H)$ Quantification of circulating $\mathrm{YFP}^{+}$pancreatic cells (CPCs). CPC numbers (per milliliter of blood) for KPCY or $\mathrm{KPCYA}^{-/-}$mice were $1.3 \pm 1.0$ or $1.1 \pm 0.5$ for CY control, $37.5 \pm 7.0$ or $8.1 \pm$ 6.1 for PanINs, and $93.7 \pm 8.8$ or $0.8 \pm 0.6$ for PDA. Mean \pm SEM. $\left({ }^{*}\right) P<0.05 . n=5$ per group. 
of $\mathrm{ADM}$ and PanIN lesions in $\mathrm{KPCYA}^{-/+}$mice were significantly slower than in age- and sex-matched KPCY mice, with lower PDA and metastasis incidence and prolonged survival compared with KPCY mice (Fig. 2G; Supplemental Fig. S2L-P). The average survival for KPCY and $\mathrm{KPCYA}^{-/+}$mice was $5.2 \pm 1.2 \mathrm{mo}$ and $8.5 \pm 2.3 \mathrm{mo}$, respectively. All of the $12 \mathrm{KPCYA}^{-/-}$mice in the cohort were alive at $12 \mathrm{mo}$ and free of cancer at the time of harvest (Fig. 2G). Thus, ATDC expression is required for PDA initiation in a dose-dependent manner, and its inactivation results in prolonged survival in KPCY mice.

Lineage tracing studies have demonstrated that individual pancreatic cells cross the basement membrane in PanIN lesions prior to the development of invasive disease; similarly, $\mathrm{YFP}^{+}$circulating pancreatic neoplastic cells (CPCs) are detected in the bloodstream prior to PDA formation in KPCY mice (Rhim et al. 2012). To determine whether ATDC similarly promotes invasion during early stages of carcinogenesis, we examined the effect of ATDC knockout on the numbers of CPCs in the bloodstream during various stages of tumorigenesis. $\mathrm{YFP}^{+}$CPCs were significantly increased in the blood of KPCY mice harboring PanINs or PDA compared with age-matched CY mice ( $n=5$ mice per group) (Fig. $2 \mathrm{H}$ ). However, ATDC deficiency markedly reduced the number of $\mathrm{YFP}^{+} \mathrm{CPC}$ in the bloodstream in $\mathrm{KPCYA}^{-/-}$mice versus age-matched KPCY mice (Fig. 2H). Using immunofluorescence staining, we demonstrated that ATDC and CK19 were coexpressed in $\mathrm{YFP}^{+}$CPCs in 6-mo-old KPCY mice (Supplemental Fig. S2Q; Supplemental Table 1), supporting our previous results that ATDC plays an essential role in the invasive phenotype of PDA /Wang et al. 2015).

\section{ATDC is required for cerulein-induced ADM-to-PanIN} progression in the context of KRAS ${ }^{G 12 D}$ expression

Cerulein-induced acute pancreatitis promotes transient ADM followed by reversion to normal acinar morphology (Strobel et al. 2007) and can significantly accelerate the development of ADM/PanIN lesions in the presence of mutant KRAS (Carrière et al. 2009). To assess whether ATDC is required during inflammation-induced PanIN formation, we studied the effect of cerulein treatment on wildtype (WT) or Pdx1-Cre ${ }^{+}$Rosa ${ }^{L S L-Y F P} ; \mathrm{Atdc}^{-/-}\left(\mathrm{CYA}^{-/-}\right)$ and $\mathrm{Kras}^{\mathrm{LSL}-\mathrm{G12D/+}}$; Pdx1-Cre ${ }^{+}$; Rosa ${ }^{L S L-Y F P}$ (KCY) mice or their Atdc-null counterpart $\left(\mathrm{KCYA}^{-/}\right)$. Mice were treated with supraphysiological doses of $250 \mathrm{mg} / \mathrm{kg}$ cerulein daily for $5 \mathrm{~d}$ followed by $7 \mathrm{~d}$ of recovery (Supplemental Fig. S3A; Ardito et al. 2012). One day following treatment, the pancreata, irrespective of genotype, exhibited an acute pancreatitis-induced metaplastic phenotype, as evidenced by replacement of acinar tissue with ADM lesions and extensive inflammatory infiltrate (Fig. 3A). The pancreata demonstrated a decrease of amylase expression (Fig. 3A,B), an enhanced proliferative response (Fig. 3C; Supplemental Fig. S3B), and replacement of acinar tissue with CK19- and SOX9-positive and MUC5ac- and Alcian blue-negative ADM lesions (Fig. 3D; Supplemental Fig. S3C,D). These data suggest that pancreatic injury can induce ADM-initiating cues independent of ATDC.

The finding that acute pancreatitis causes ADM initiation even in the absence of ATDC raised the question of whether ATDC-deficient acinar cells can undergo acinar ductal reprogramming and form PanINs if expression of oncogenic KRAS is combined with pancreatic injury. We found that after $7 \mathrm{~d}$ of recovery, ADM lesions reverted to normal acinar morphology in WT and $\mathrm{CYA}^{-/-}$mice, along with a basal proliferative rate and expression of amylase, CK19, MUC5ac, and SOX9 (Fig. 3A-D, Supplemental Fig. S3B-F; Supplemental Table 2). However, in KCY mice, there was almost complete replacement of pancreatic tissue with fibrosis, infiltration of inflammatory cells, and widespread ADM/PanIN lesions with characteristic loss of amylase-expressing acinar tissue, accompanied by cuboidal to columnar duct-like structures with enlarged lumens positive for CK19, SOX9, Alcian blue, and MUC5ac (Fig. 3A-G; Supplemental Fig. S3B-F; Supplemental Table 2). In stark contrast to KCY mice, ATDC knockout in the $\mathrm{KCYA}^{-/-}$mice inhibited $\mathrm{KRAS}^{\mathrm{G} 12 \mathrm{D}}$ induced ADM-to-PanIN progression, with pancreata resembling those of WT mice (Fig. 3A-G; Supplemental Fig. S3B-F; Supplemental Table 2).

To assess the status of ATDC expression during cerulein-induced ADM formation, we evaluated pancreatic sections from the different groups of mice. As shown in Figure $3 \mathrm{H}$ and Supplemental Figure S3F, ATDC expression was not altered during pancreatitis-related ADM formation immediately following cerulein treatment in WT mice. However, in the presence of KRAS ${ }^{\mathrm{G} 12 \mathrm{D}}$, cerulein-induced ADM efficiently progressed into PanIN lesions, and, during this acinar-to-ductal reprogramming period, ATDC expression was significantly up-regulated (Fig. $3 \mathrm{H}, \mathrm{I}$; Supplemental Fig. S3F). Because of the kinetics of ATDC expression and the fact that KCY and $\mathrm{KCYA}^{-/-}$ pancreatic tissue histological features differed at day 7 after cerulein treatment, we evaluated cell proliferation, apoptosis, and $\beta$-catenin and SOX9 expression at day 3 , an intermediate time point when ATDC expression becomes detectable in ADM lesions that progress to PanIN. As shown in Supplemental Figure S3G, the number of Ki67positive cells at days 3 and 7 was reduced in $\mathrm{KCYA}^{-/-}$ mice compared with KCY controls. Consistent with previously published data (Zhang et al. 2014), we observed a small and persistent fraction of apoptotic cells, which was maintained throughout day 7 in KCY mice but decreased to almost undetectable levels in $\mathrm{KCYA}^{-/-}$mice at day 7 (Supplemental Fig. S3H). Expression of total $\beta$-catenin (Supplemental Fig. S3I-K), nonphosphorylated (activated) $\beta$-catenin (Supplemental Fig. S3J-L), and Sox9 (Supplemental Fig. S3N) increased over the 7-d period in $\mathrm{KPC}$ mice but was reduced in $\mathrm{KCYA}^{-/-}$mice at days 3 and 7 after treatment. Conversely, we observed a decrease in the level of inhibitory phosphorylation (phosphoSer33,37 and Thr41) of $\beta$-catenin from day 1 to day 7 in KCY mice (Supplemental Fig. S3J,M), while it increased in $\mathrm{KYCA}^{-/-}$mice. Therefore, loss of ATDC prevents the establishment of sustained $\beta$-catenin and Sox 9 signaling, thus inhibiting $\mathrm{Kras}^{\mathrm{G} 12 \mathrm{D}}$-driven proliferation and 
A

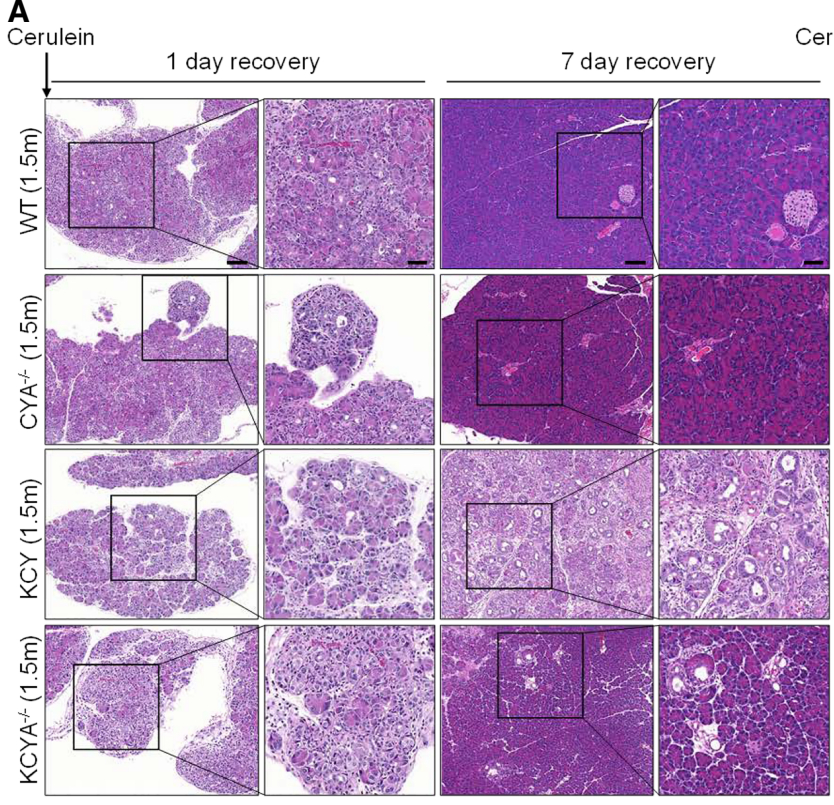

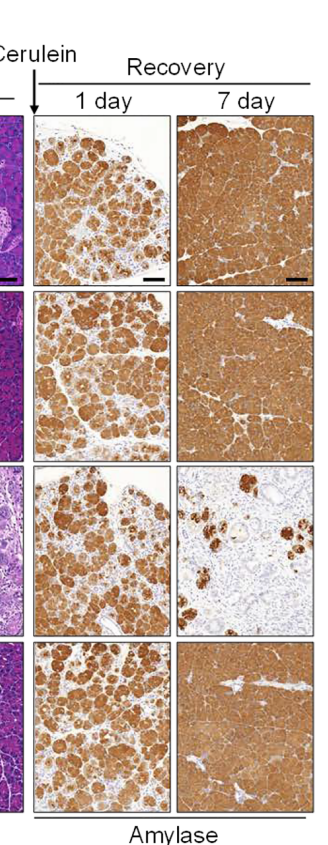

D

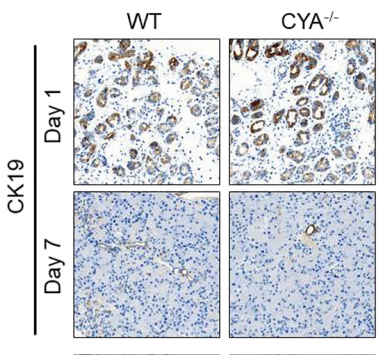

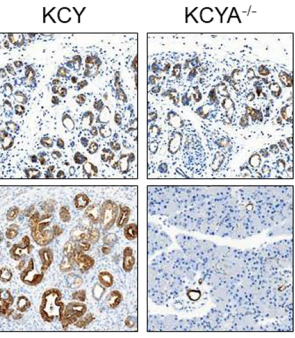
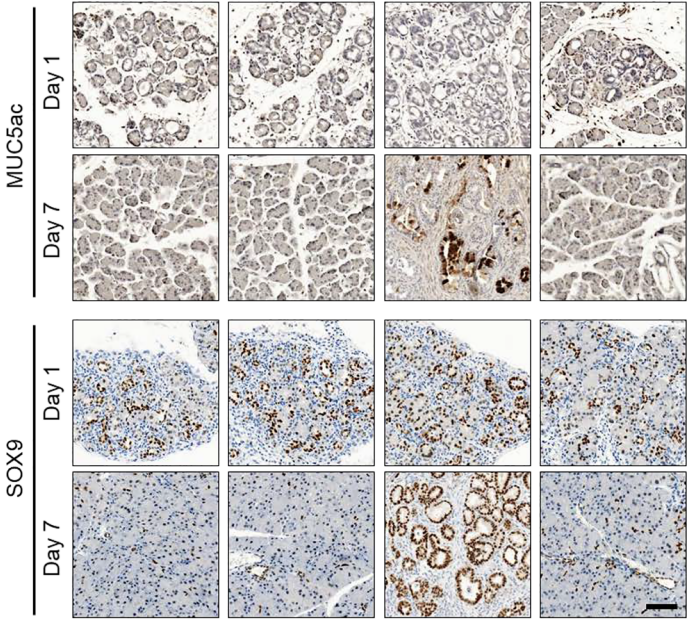

E

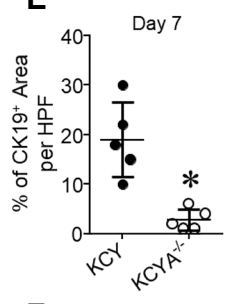

$\mathbf{F}$

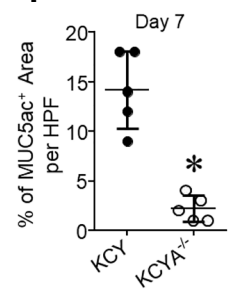

H
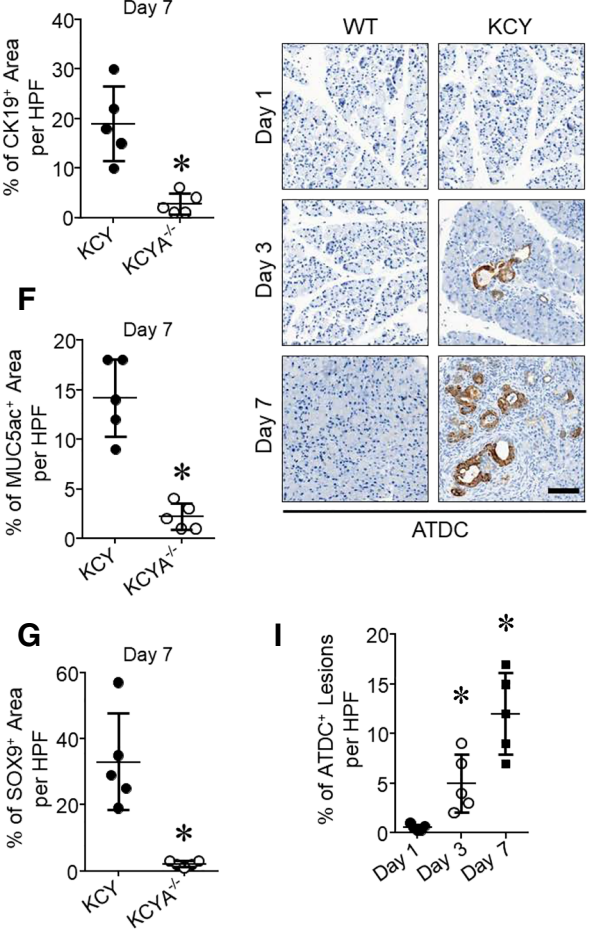
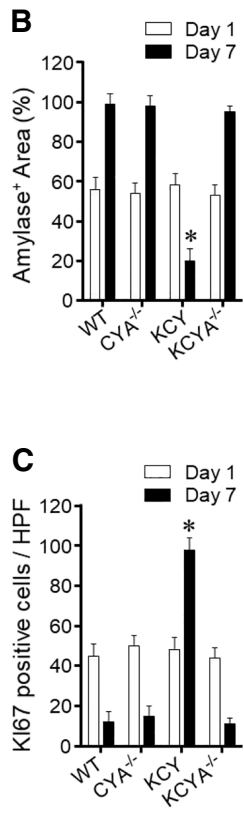

Figure 3. ATDC is required for cerulein-induced ADM-to-PanIN progression in the context of KRAS ${ }^{\mathrm{G} 12 \mathrm{D}}$ expression in the pancreas. (A) WT, CYA ${ }^{-/-}$, KCY, and KCYA ${ }^{-1-} 1.5$-mo-old mice were treated with $250 \mu \mathrm{g} / \mathrm{kg}$ cerulein once daily for $5 \mathrm{~d}$ and allowed to recover for up to $7 \mathrm{~d}$. Sections were stained with H\&E (left; scale bar, $100 \mu \mathrm{m}$; inset scale bar, $50 \mu \mathrm{m}$ ) or for amylase expression (right; scale bar, $50 \mu \mathrm{m})$. (B) Quantitation of the percentage of amylase-positive areas in the pancreata from different animal groups at day 1 and day 7 after treatment. $n=5$ per group $\left(^{*}\right) P<0.05$ versus $\mathrm{KCYA}^{-/-}$at day 7. $(C)$ Quantitation of the KI67-positive cells by counting at least four individual 200× optical high-power fields (HPFs) in pancreata from the different animal groups. $n=5$ per group. $\left({ }^{*}\right) P<0.05$ versus $\mathrm{KCYA}^{-/-}$at day 7. $(D)$ Representative immunohistochemical staining of CK19, MUC5ac, and SOX9 in pancreatic sections from 1.5 -mo-old KPCY or KPCYA ${ }^{-1-}$ mice 1 or $7 \mathrm{~d}$ after cerulein treatment $(250 \mu \mathrm{g} / \mathrm{kg}$ cerulein per day for $5 \mathrm{~d})$. Scale bar, $50 \mu \mathrm{m}$. (E-G) Quantification of the percentage of $\mathrm{CK} 19^{+}(E),{\operatorname{MUC} 5 \mathrm{ac}^{+}(F) \text {, or SOX9 }}^{+}(G)$ lesions per high-power field $(\mathrm{HPF}) 7 \mathrm{~d}$ after cerulein treatment in 1.5-mo-old KCY or KCYA ${ }^{-1-}$ mice. Magnification, 400x; three random fields per mouse; normalization per field. Each point represents a single mouse, and horizontal bars represent the mean percentage for each group. $\left.{ }^{*}\right) P<0.05$. $(H)$ Representative immunohistochemical staining of ATDC in pancreatic sections from 1.5-mo-old WT or KPCY mice 1, 3, or $7 \mathrm{~d}$ of recovery after cerulean treatment $(250 \mu \mathrm{g} / \mathrm{kg}$ cerulein per day for $5 \mathrm{~d}$ ). Scale bar, $50 \mu \mathrm{m}$. (I) Quantification of the percentage of ATDC ${ }^{+}$lesions per high-power field (HPF) 1,3, or $7 \mathrm{~d}$ after cerulein treatment in 1.5-mo-old WT or KCY mice. Magnification, 400x; three random fields per mouse; normalization per field. Each point represents a single mouse, and horizontal bars represent the mean percentage for each group. $(*) P<0.05$. 
allowing redifferentiation of ductal cells to acinar cells after ADM.

Collectively, our data indicate that ATDC is essential for $\mathrm{KRAS}^{\mathrm{G} 12 \mathrm{D}}$-mediated ADM-to-PanIN progression in response to acute pancreatitis. Based on these findings, we assessed whether ATDC was expressed in ADMs that form spontaneously during the tumorigenic process in KCY mice. Indeed, ATDC was expressed in these lesions, highlighting its role in the ADM process (Supplemental Fig. S3O). Consistent with our previous data, ATDC overexpression significantly promoted PanIN lesion progression in GFP-KRAS ${ }^{\mathrm{G} 12 \mathrm{D}}$ primary ductal epithelial cell (PDEC) orthotopic xenografts (Supplemental Fig. S3P-S; Pylayeva-Gupta et al. 2012; Wang et al. 2015). In GEM models, other signaling molecules have also been shown to provide tumor-protective phenotypes in the setting of oncogenic Kras, including Yap1 (Gruber et al. 2016; Jiang et al. 2018; Rozengurt et al. 2018), IKK2 (Ling et al. 2012), Stat3 (He et al. 2010; Corcoran et al. 2011), Klf4 (Wei et al. 2016), and Klf5 (He et al. 2018). We therefore tested whether ATDC modulated the expression of Yap1, IKK2, or Klf4 in GFP-KRAS ${ }^{\mathrm{G} 12 \mathrm{D}}$ PDECs. As shown in Supplemental Figure S3T, these proteins were detectable in control GFPKRAS ${ }^{\text {G12D }}$ PDECs that do not express ATDC, indicating that ATDC is not required for their expression, at least in this model, counter to what was observed with activated $\beta$-catenin and Sox9 (Supplemental Fig. S3T,U).
ATDC is required for KRAS $\mathrm{G12D}^{- \text {induced acinar-to- }}$ ductal transdifferentiation in three-dimensional (3D) primary acinar cell cultures

Since multiple lines of evidence suggest that ADM is a source of neoplasia in the initiation of human PDA, we used an additional experimental approach to evaluate the contribution of ATDC to KRAS ${ }^{\mathrm{G} 12 \mathrm{D}}$-driven ADM. Primary pancreatic acinar cells were isolated from 1.5-moold KCY or $\mathrm{KCYA}^{-/-}$mice, embedded in a collagen gel, and placed in 3D cultures for $5 \mathrm{~d}$. KCY acinar cells grown in 3D cultures underwent ADM, forming large duct-like structures. The samples at $5 \mathrm{~d}$ presented as a single layer of cells surrounding a clear lumen, characteristic of a mature ductal structure as described (Fig. 4A,B; Ardito et al. 2012). The lack of ATDC in acinar cells from $\mathrm{KCYA}^{-/-}$ mice significantly attenuated KRAS ${ }^{\mathrm{G} 12 \mathrm{D}}$-induced acinar cell transdifferentiation and ADM formation (Fig. 4C). Time-dependent gain of the ductal marker CK19 and down-regulation of amylase expression were observed in acinar cells isolated from KCY mice (Fig. 4D,E). These changes were significantly inhibited by ATDC knockout in $\mathrm{KCYA}^{-/-}$acinar cell 3D cultures (Fig. 4D,E). Consistent with our data in KCY mice, Atdc mRNA and protein levels were significantly up-regulated in YFP-positive KCY acinar cells 3 and $5 \mathrm{~d}$ after being placed in 3D cultures when ADM lesions are present (Fig. 4F; Supplemental
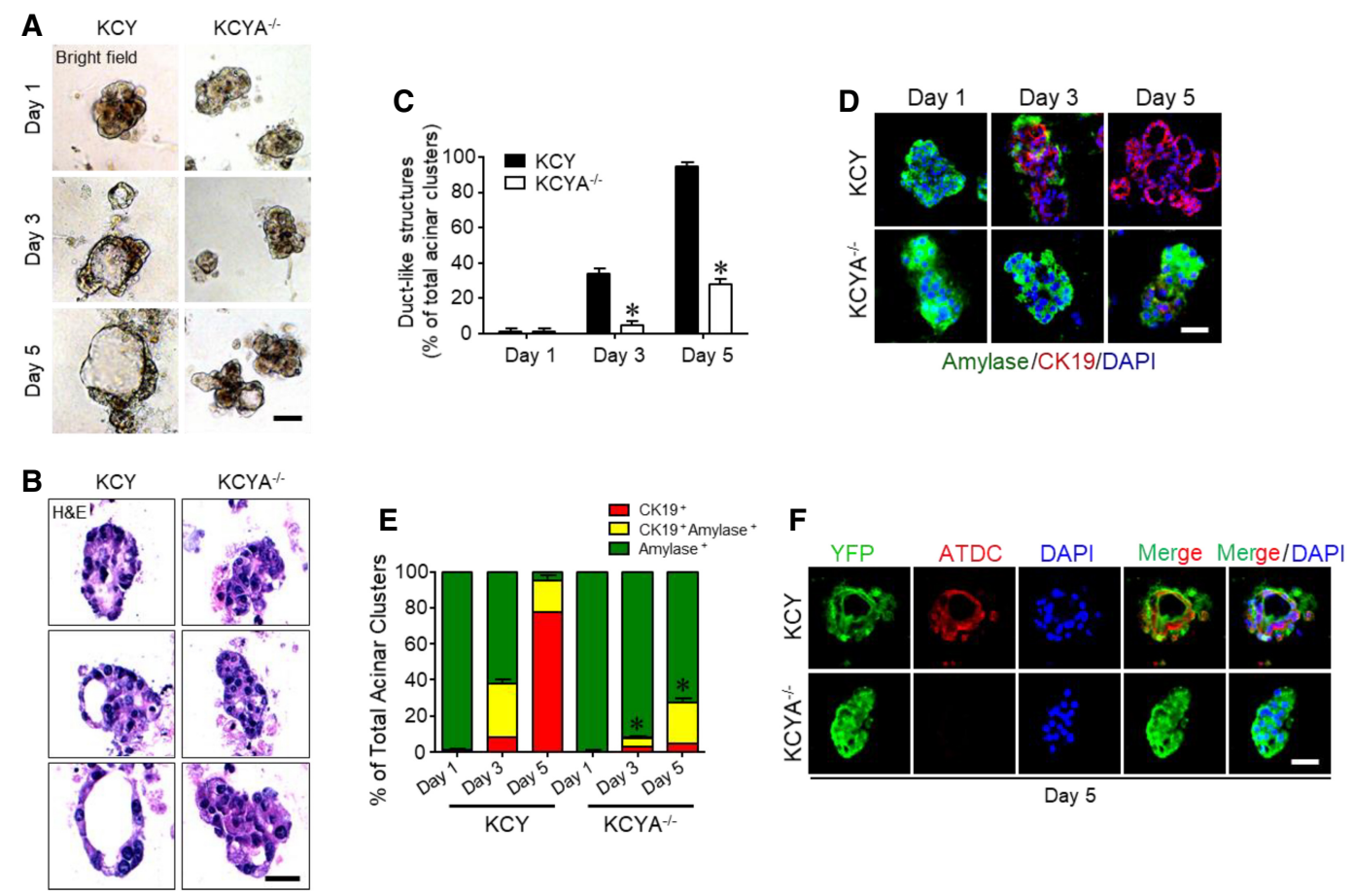

Figure 4. ATDC is required for KRAS ${ }^{\mathrm{G} 12 \mathrm{D}}$-induced acinar-to-ductal transdifferentiation in primary acinar $3 \mathrm{D}$ cultures. $(A, B)$ Representative bright-field light microscopy $(A)$ and H\&E staining $(B)$ at days 1,3 , and 5 of primary acinar cell 3D cultures from 1.5-mo-old KCY and $\mathrm{KCYA}^{-1-}$ mice. Scale bar, $20 \mu \mathrm{m}$. (C) Quantification of duct-like structures in $A$ at days 1,3 , and 5 following acinar cell $3 \mathrm{D}$ culture. Mean \pm SE. $\left({ }^{*}\right) P<0.05$ versus KCY. $n=3$. (D) Coimmunofluorescence staining of amylase (green), CK19 (red), and DAPI (blue) in acinar cell 3D cultures from 1.5-mo-old KCY and $\mathrm{KCYA}^{-1-}$ mice at days 1, 3, and 5. Scale bar, $20 \mu \mathrm{m} . n=3$. (E) Quantitation of amylase or CK19 singleor double-positive acinar clusters in $D .\left(^{*}\right) P<0.05$ versus KCY. $n=3$. ( $F$ ) Coimmunofluorescence staining of YFP (green), ATDC (red), and DAPI (blue) in acinar cell 3D cultures at day 5 from 1.5 -mo-old $\mathrm{KCY}$ and $\mathrm{KCYA}^{-/-}$mice. Scale bar, $20 \mu \mathrm{m} . n=3$. 
Fig. S4A,B). These data indicate that endogenous ATDC expression is up-regulated in acinar cells during

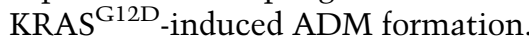

\section{Inactivation of ATDC does not affect RAS activity}

It has been shown previously that continuous expression of oncogenic KRAS is required for PanIN formation and progression and cancer maintenance in the iKras model, allowing inducible and reversible expression of oncogenic KRAS (Collins et al. 2012). In addition, stimuli that generate prolonged RAS signaling in the setting of oncogenic KRAS accelerate PanIN formation (Ardito et al. 2012; Daniluk et al. 2012). Therefore, we measured RAS activity in acinar cells expressing oncogenic KRAS activity in the presence and absence of ATDC. KRAS activity was elevated in KCY mice compared with WT mice; however, RAS activity levels were similar in acinar cells isolated from KCY and $\mathrm{KCYA}^{-/-}$mice (Supplemental Fig. S5), suggesting that inhibition of RAS activity is not the mechanism by which knockout of ATDC blocks oncogenic KRAS-induced ADM-to-PanIN progression.

\section{$\beta$-Catenin signaling activated by ATDC is required for KRAS $S^{G 12 D}$-induced ADM formation}

$\beta$-Catenin has also been reported previously to play a functional role in the process by which acinar cells undergo $\mathrm{ADM}$ and pancreatic carcinogenesis (Pasca di Magliano et al. 2007; Zhang et al. 2013). We demonstrated previously that ATDC promotes proliferation and invasion of human pancreatic cancer cells by activation of $\beta$-catenin signaling (Wang et al. 2009, 2015). To determine whether the ability of ATDC to impact ADM formation was mediated through its activation of canonical $\beta$-catenin signaling, we used our $3 \mathrm{D}$ culture system to assess ADM in KCY and $\mathrm{KCYA}^{-/-}$mice. Acinar cells placed in the 3D cultures at day 1 showed very low membrane localization of $\beta$-catenin in GFP-positive acinar cells isolated from KCY or $\mathrm{KCYA}^{-/-}$mice (Fig. 5A). However, as ADM lesions developed over the $5 \mathrm{~d}$ in culture, we observed enhanced total and nuclear localization of $\beta$-catenin in cells derived from KCY mice (Fig. 5A; Supplemental Fig. S6A), which was blocked by knockout of ATDC (Fig. 5A; Supplemental Fig. S6A). To determine whether $\beta$-catenin signaling was required for ATDC to drive $\mathrm{ADM}$ in context with KRAS $^{\mathrm{G} 12 \mathrm{D}}$, we introduced a lentiviral $\beta$-catenin expression vector into $3 \mathrm{D}$ cultures from $\mathrm{KCYA}^{-1-}$ mice and observed that this was effective in restoring ADM formation (Fig. 5B-D). Overall, these data indicate that ATDC induces $\mathrm{ADM}$ formation through $\beta$-catenin signaling.

\section{ATDC increases SOX9 expression in KRAS ${ }^{G 12 D}$-induced $A D M$ via $\beta$-catenin signaling}

Recent studies have indicated that the transcription factor SOX9 is critical for PDA initiation and is required for ADM/PanIN progression to PDA in mouse models (Kopp et al. 2012; Prévot et al. 2012; Chen et al. 2015).
Because the phenotype of ATDC knockout mimicked the impact of SOX9 depletion on ADM/PanIN progression in cerulein-treated KC mice, we evaluated whether ATDC might play a role in driving SOX9 expression. We observed that Sox 9 expression was up-regulated in KCY acinar 3D cultures $5 \mathrm{~d}$ after plating, the time frame in which ADM lesions formed (Fig. 5E; Kopp et al. 2012). In contrast, Sox 9 mRNA levels were significantly lower in $\mathrm{KCYA}^{-/-}$acinar 3D cultures (Fig. 5E). SOX9 protein was coexpressed with ATDC in ADM and PanIN lesions in KPCY mice, while its expression was markedly decreased in pancreatic sections from $\mathrm{KPCYA}^{-/-}$mice (Fig. 5F; Supplemental Fig. S6B,C). Overexpression of $\beta$-catenin effectively rescued the expression of Sox 9 in acinar $3 \mathrm{D}$ cultures from $\mathrm{KCYA}^{-/-}$mice at day 5 (Fig. $5 \mathrm{G}$ ), indicating that ATDC's ability to up-regulate SOX9 expression was mediated through $\beta$-catenin signaling.

Knockout of ATDC inhibits KRAS $S^{G 12 D}$-induced ADM via SOX9 down-regulation

To evaluate whether the ability of ATDC to regulate ADM formation was mediated through $\beta$-catenin-driven SOX9 activity, we used lentiviral constructs to target SOX9 expression and found that SOX9 knockdown significantly inhibited KRAS ${ }^{\mathrm{G} 12 \mathrm{D}}$-induced ADM formation, mimicking the effects observed with knockdown of ATDC (Fig. 6A-C). Furthermore, SOX9 expression was able to restore ADM formation in acinar $3 \mathrm{D}$ cultures from $\mathrm{KCYA}^{-/-}$mice to levels observed in KCY mice, demonstrating that $\mathrm{SOX} 9$ is a key downstream effector of ATDC in this setting (Fig. 6D-F). Notably, we observed coexpression of $\beta$-catenin with SOX9 in the ADM lesions that developed in the KCY acinar 3D cultures (Fig. 6G). Similar to loss of ATDC, knockdown of $\beta$-catenin blocked SOX9 expression at day 5 in acinar 3D cultures from KCY mice (Fig. 6G). Overall, these results show that ATDC promotes ADM by up-regulating SOX9 expression via $\beta$-catenin signaling.

Expression of ATDC, $\beta$-catenin, and SOX9 is increased in human ADM lesions and PDA

To determine the human relevance of these findings, we examined ATDC expression in ADM lesions from 12 samples of human pancreatic tissue (obtained from patients who underwent resection for chronic pancreatitis $[n=5]$ or PDA $[n=7]$, the latter in areas of fibrosis away from the tumor). Expression of ATDC was elevated in human ADM lesions (Fig. 7A,B), indicating that aberrant expression of ATDC not only is a hallmark of established PDA but also defines precancerous ADM lesions. To evaluate whether the ATDC/ $\beta$-catenin/SOX9 signaling axis is activated in human ADM, we performed coimmunofluorescence staining of ATDC and $\beta$-catenin or ATDC and SOX9 in the same set of samples and confirmed that all three proteins were coexpressed in human ADM lesions (Fig. 7C,D; Supplemental Table 3).

Because ATDC is expressed throughout the progression from $\mathrm{ADM}$ to PDA, we further investigated whether the 
A
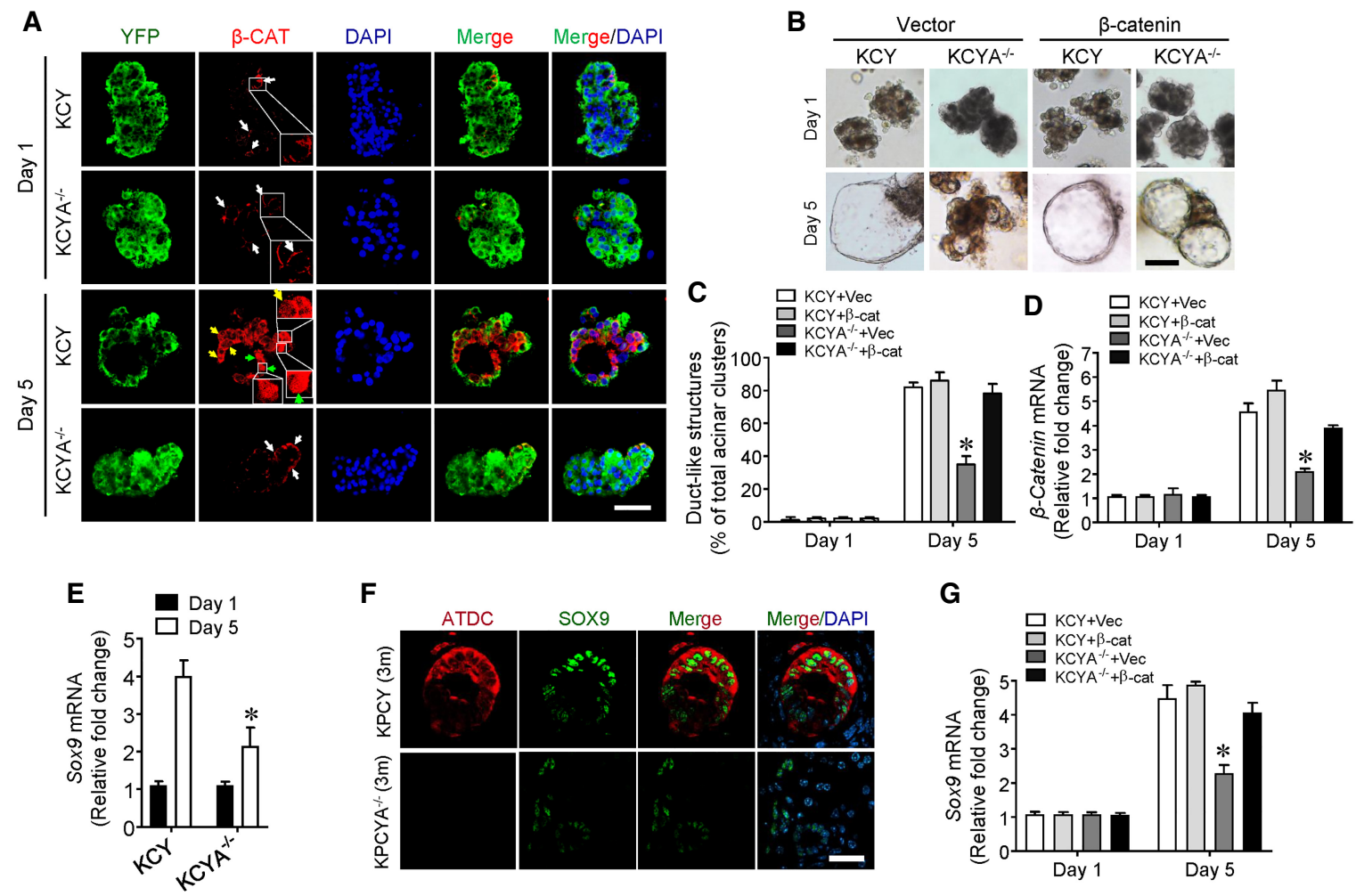

$\mathbf{F}$

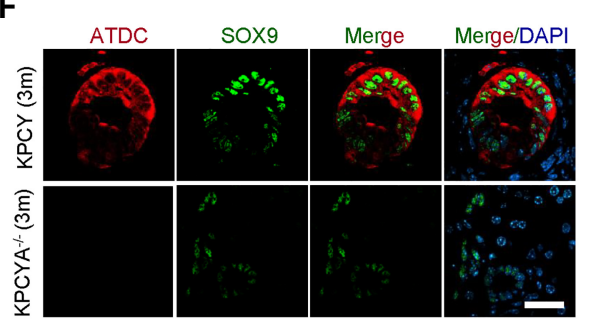

G

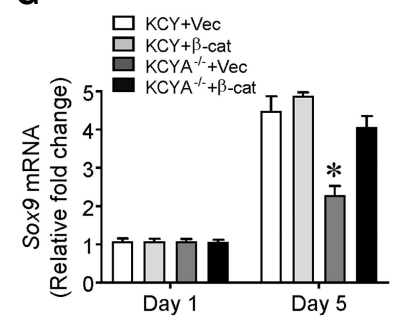

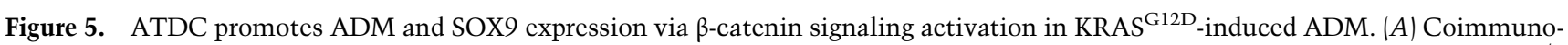
fluorescence staining of YFP (green), $\beta$-catenin ( $\beta$-cat; red), and DAPI (blue) in acinar cell 3D cultures from 1.5-mo-old KCY and KCYA ${ }^{-/-}$ mice. At day 1 , very low expression of $\beta$-catenin in acinar cells is confined to the plasma membrane (white arrow). In contrast, cytoplasmic (yellow arrows) or nuclear (green arrows) $\beta$-catenin staining was observed in $\mathrm{KRAS}^{\mathrm{G} 12 \mathrm{D}}$-induced ADM lesions generated in acinar cell 3D

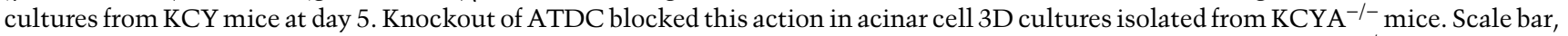
$20 \mu \mathrm{m} . n=3$. (B) Representative bright-field light microscopy of acinar cell 3D cultures from 1.5-mo-old KCY or KCYA ${ }^{-/-}$mice at days 1 and 5. Primary acinar cells were infected with $\beta$-catenin ( $\beta$-cat) or empty lentiviral vector $($ Vec). Scale bar, $20 \mu \mathrm{m} . n=3$. $(C) \mathrm{Quantification}$ of duct-like structures in $B$ at days 1 and 5 following acinar cell $3 \mathrm{D}$ cultures from 1.5 -mo-old $\mathrm{KCY}$ or $\mathrm{KCYA}^{-/-}$mice. Mean $\pm \mathrm{SE}$. $\left(^{*}\right) P<0.05$ versus KCY + Vec. $n=3$. (D) qRT-PCR analysis of $\beta$-catenin mRNA expression in $B$ at days 1 and 5 following acinar cell 3D cultures from 1.5 -mo-old KCY or KCYA ${ }^{-/-}$mice. Mean \pm SE. $\left({ }^{*}\right) P<0.05$ versus KCY + Vec. $n=3$. The probe used recognized both endogenous and lentiviral-expressed $\beta$-catenin mRNA. (E) qRT-PCR analysis of Sox 9 mRNA expression in acinar 3D cultures at days 1 and 5 from 1.5-mo-old KCY and KCYA ${ }^{-/-}$mice. $\left({ }^{*}\right) P<0.05$ versus KCY. $n=3$. $(F)$ Coimmunofluorescence staining of SOX9 (green), ATDC (red), and DAPI (blue) in pancreatic sections from 3-mo-old KPCY and KPCYA ${ }^{-1-}$ mice. Scale bar, $50 \mu \mathrm{m} . n=5$. (G) qRT-PCR analysis of Sox9 mRNA expression at days 1 and 5 in acinar cell $3 \mathrm{D}$ cultures from 1.5 -mo-old $\mathrm{KCY}$ or $\mathrm{KCYA}^{-/-}$mice with or without $\beta$-catenin ( $\beta$-cat) overexpression. Mean \pm SE. $\left(^{*}\right) P<0.05$ versus KCY + Vec. $n=3$.

ATDC/ $\beta$-catenin/SOX9 axis remains functional in human PDA. We showed previously that ATDC activation of $\beta$ catenin signaling in human pancreatic cancer cells resulted in enhanced TCF4 transcriptional activity (Wang et al. 2009) and that TCF4 expression is significantly up-regulated in PanIN lesions from KC mice (Pasca di Magliano et al. 2007). A review of the encyclopedia of DNA elements (ENCODE) public database (The ENCODE Project Consortium 2012) revealed three TCF4-binding motifs (BM1, BM2, and BM3) in the human SOX9 gene promoter and enhancer (Supplemental Fig. S7A). Specific primers to these potential binding sites were designed (Supplemental Table 4), and targeted chromatin immunoprecipitation (ChIP) assays were performed on HPAC PDA cells and showed enrichment of TCF4 binding on BM1 and BM2 of the human SOX9 promoter in an ATDC-dependent manner (Fig. 7E). Consistent with loss of TCF4 binding to its promoter, expression of SOX9 decreased after ATDC silencing in HPAC cells (Fig. 7F), confirming that ATDC regulates, through $\beta$-catenin, SOX9 expression in PDA cells. A significant positive correlation between ATDC and SOX9 expression was observed in human TCGA (The Cancer Genome Atlas) PDA samples $(P=$ $1.05 \times 10^{-11}$ ) (Fig. 7G). Of note, a significant positive correlation was also observed in ATDC and SOX9 expression in other human malignancies, including oncogenic Krasdriven lung adenocarcinoma (LUAD; $P=8.20 \times 10^{-11}$ ) (Supplemental Fig. S7B; Supplemental Table 5; The Cancer Genome Atlas Research Network 2017), highlighting that this signaling pathway may be operant in other tumor types. Overall, these data indicate that the ATDC $/ \beta$-catenin/SOX9 signaling axis is activated during the early stages of human pancreatic tumorigenesis and remains functional in PDA. 

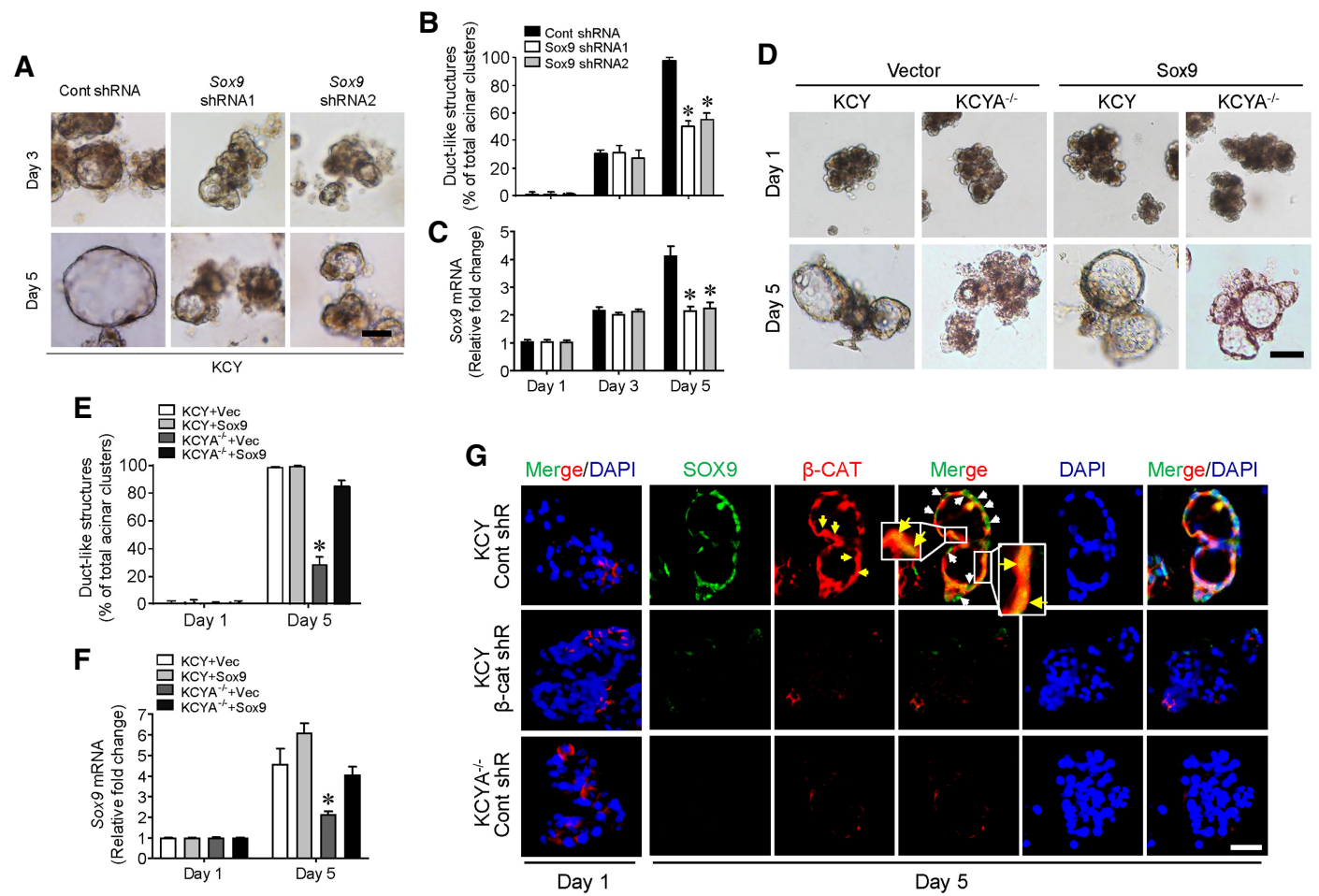

Figure 6. Knockout of ATDC inhibits KRAS ${ }^{\mathrm{G} 12 \mathrm{D}}$-induced ADM via SOX9 down-regulation. $(A)$ Representative bright-field light microscopy at days 3 and 5 of acinar cell 3D cultures from 1.5-mo-old KCY mice. Primary acinar cells were infected with lentivirus expressing control shRNA (Cont shRNA; scrambled) or two different Sox9 shRNAs (1 and 2) targeting specific regions of Sox9 mRNA. Scale bar, $20 \mu \mathrm{m} . n=3$. (B) Quantification of duct-like structures in $A$ at days 3 and 5 following acinar cell $3 \mathrm{D}$ culture. Mean $\pm \mathrm{SE}$. $\left({ }^{*}\right) P<0.05$ versus Cont shRNA. $n=3$. (C) qRT-PCR analysis of Sox 9 mRNA expression in $A$ at days 3 and 5 following acinar cell 3D culture from 1.5-mo-old KCY mice. Mean \pm SE. $\left({ }^{*}\right) P<0.05$ versus Cont shRNA. $n=3$. $(D)$ Representative bright-field light microscopy at days 1 and 5 following acinar cell 3D culture from 1.5-mo-old KCY and $\mathrm{KCYA}^{-1-}$ mice. Primary acinar cells were infected with empty vector (Vec) or Sox 9 lentiviral expression vector. Scale bar. $20 \mu \mathrm{m} . n=3$. (E) Quantification of duct-like structures in $D$ at days 1 and 5 following acinar cell 3D culture. Mean \pm SE. $\left(^{*}\right) P<0.05$ versus KCY + Vec. $n=3$. $(F)$ qRT-PCR analysis of Sox 9 mRNA expression in $D$ at days 1 and 5 following acinar cell $3 \mathrm{D}$ culture from 1.5 -mo-old $\mathrm{KCY}$ and $\mathrm{KCYA}^{-/-}$mice. Mean $\pm \mathrm{SE}$. $\left(^{*}\right) P<0.05$ versus KCY + Vec. $n=3$. The probe used recognized both endogenous and lentiviral-expressed Sox 9 mRNA. $(G)$ Coimmunofluorescent staining of SOX9 (green), $\beta$-catenin ( $\beta$-cat; red), and DAPI (blue) in 3D cultured acinar cells expressing $\beta$-catenin shRNA ( $\beta$-cat shR) or control shRNA (Cont shR) isolated from 1.5-mo-old $\mathrm{KCY}$ and acinar cells isolated from $\mathrm{KCYA}^{-/-}$mice. At day 1, low plasma membrane staining of $\beta$-catenin and negative staining of SOX9 were observed in 3D cultured acinar cells. Nuclear staining of SOX9 (white arrows), cytoplasmic or nuclear staining of $\beta$-catenin (yellow arrows), and nuclear coexpression of $\beta$-catenin and SOX9 (yellow) was exhibited in KRAS ${ }^{\mathrm{G} 12 \mathrm{D}}$-induced ADM lesions generated in $3 \mathrm{D}$ cultures from KCY mice at day 5 . Knockout of ATDC or knockdown $\beta$-catenin inhibited these actions. Scale bar, $10 \mu \mathrm{m}$. $n=3$.

\section{Discussion}

ATDC is highly expressed in multiple tumor types and is typically a marker of invasive and aggressive tumors (Hatakeyama 2016). In human pancreatic cancer cells, ATDC has been shown to promote cell proliferation and invasion via activation of the $\beta$-catenin/TCF4 signaling pathway (Wang et al. 2009). More recently, ATDC has been identified as a proximal regulator of EMT in KRASdriven pancreatic cancer in vivo (Wang et al. 2015). Based on these previous findings, we hypothesized that ATDC knockout in the aggressive KPCY pancreatic cancer model would block the invasive switch and decrease tumor growth and metastasis. Instead, we observed a complete block of ADM formation, and no tumors developed in KPCY ATDC knockout animals over the 12-mo period of study, resulting in one of the most profound levels of inhibition of tumor formation observed in this model to date
(Baer et al. 2014; Garcia et al. 2014; Mazur et al. 2014; Whittle et al. 2015; Zheng et al. 2015; Kugel et al. 2016; Seifert et al. 2016; Shen et al. 2017).

ADM represents a mechanism of cellular reprogramming in response to external stress signals and initiates pancreatic regeneration of damaged epithelial cells (Maitra and Hruban 2008). In pancreatitis injury models, acinar cells contribute to the regeneration of the damaged exocrine compartment through an intermediary process of dedifferentiation, with transient acquisition of a developmental transcriptional program followed by redifferentiation into mature acinar cells (Strobel et al. 2007). In GEM models in which pancreatic cells express oncogenic KRAS, correct acinar cell redifferentiation is blocked, leading to ADM that becomes reprogrammed to be irreversible. These ADM lesions are considered to be a source of PanIN lesions that, in the setting of inflammation and oncogenic KRAS, have accelerated progression to PanIN 
Wang et al.
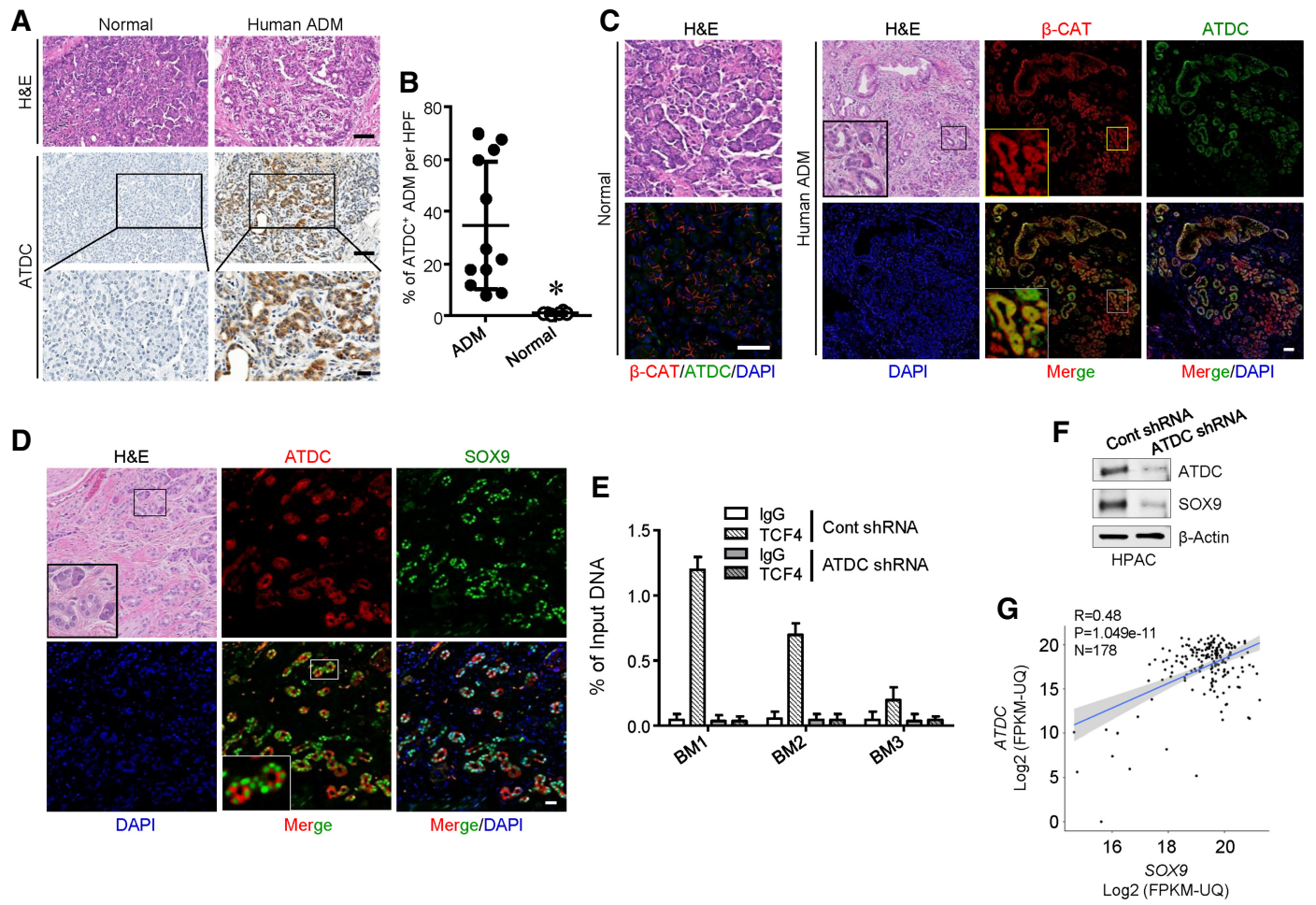

Figure 7. ATDC and SOX9 colocalize in human ADM lesions. (A) Representative immunohistochemical images of ATDC expression in human normal pancreas or ADM samples. Scale bar, $50 \mu \mathrm{m} . n=12 \mathrm{ADM} ; n=9$ normal. The bottom panels are magnified views of the box. Scale bar, $20 \mu \mathrm{m}$. (B) Quantification of the percentage of $\mathrm{ATDC}^{+} \mathrm{ADMs}$ per high-power field (HPF) in human normal pancreas or ADM samples. Magnification, 400×; three random fields per sample; normalization per field. Each point represents a single patient, and horizontal bars represent the mean percentage for each group. $\left(^{*}\right) P<0.05$. $(C) \mathrm{H} \& \mathrm{E}$ and coimmunofluorescence staining of $\beta$-catenin (red), ATDC (green), and DAPI (blue) in human normal and ADM sections. (Black inset) ADM. Scale bar, $100 \mu \mathrm{m} .(D) \mathrm{H} \& \mathrm{E}$ and coimmunofluorescence staining of SOX9 (green), ATDC (red), and DAPI (blue) in human ADM lesions. (Black inset) ADM; (white inset) ATDC/SOX9 coexpression. Scale bar, $100 \mu \mathrm{m} . n=3$ per group. (E) Chromatin immunoprecipitation (ChIP) assays performed using ChIP-grade anti-TCF4-specific antibody or normal rabbit IgG in HPAC cells with or without ATDC shRNA expression. $(F)$ Western blot analysis of SOX9 in HPAC cells in response to ATDC knockdown. (G) ATDC and SOX9 mRNA expression level correlates in The Cancer Genome Atlas (TCGA) pancreatic adenocarcinoma cohort (black dots). $n=178$. Linear model smoothing (blue line) and confidence interval (gray shading) are shown.

and PDA development in mouse models (Guerra et al. 2007; De La et al. 2008; Carrière et al. 2009|. Published evidence has shown that ADM is a precursor to neoplasia in the initiation of human PDA (Hruban et al. 2008).

To dissect out the role of ATDC in ADM formation, we induced acute pancreatitis with cerulein in WT mice and mice expressing oncogenic KRAS with and without knockout of ATDC. Lack of ATDC did not preclude ADM formation in any of the genetic backgrounds tested, indicating that it is not required for ADM formation. After $7 \mathrm{~d}$ of recovery, ADM lesions had returned to normal acinar morphology in WT mice, unlike KCY mice, which displayed widespread ADM/PanIN lesions. In contrast to KCY mice, KCY mice lacking ATDC exhibited a return to normal acinar morphology, highlighting the requirement of ATDC for oncogenic KRAS to promote tumorigenesis in this setting. Interestingly, we noted that ATDC expression following cerulein treatment occurred only in the presence of oncogenic KRAS but was not evident until $3 \mathrm{~d}$ after treatment. We showed previously that ATDC is up-regulated in response to oncogenic KRAS during tumorigenesis (Wang et al. 2015). A detailed accounting of the signaling events by which oncogenic KRAS induces ATDC expression in the context of ADM formation remains to be elucidated.

We demonstrated previously that ATDC uses $\beta$-catenin signaling to promote tumorigenesis in later stages of the neoplastic process (Wang et al. 2009, 2015). It has been shown that $\beta$-catenin signaling and the TCF4 transcription factor are required for SOX9 expression in epithelial cells (Blache et al. 2004), and several reports have indicated that SOX9 expression is associated with $\beta$-catenin signaling in bladder, lung, colon, and ovarian tumorigenesis (Blache et al. 2004; Ahmad et al. 2011; Pacheco-Pinedo et al. 2011). In addition, coactivation of KRAS ${ }^{\mathrm{G} 12 \mathrm{D}}$ and $\beta$-catenin signaling promoted lung cancer formation and up-regulated SOX9 expression in $C C 10^{C r e} \mathrm{Ctnnb}^{\text {ex3ff; }}$; LSL-Kras ${ }^{G 12 D}$ mice (Pacheco-Pinedo et al. 2011).

Consistent with previous reports, we found that $\beta$-catenin expression and nuclear localization as well as SOX9 expression were dramatically increased in KRAS ${ }^{\mathrm{G} 12 \mathrm{D}}$. induced $\mathrm{ADM}$ lesions generated in $3 \mathrm{D}$ cultures from KCY mice. However, knockout of ATDC inhibited $\beta$-catenin and SOX9 expression and consequently blocked 
KRAS $^{\mathrm{G} 12 \mathrm{D}}$-induced ADM formation. In studies linking $\beta$-catenin to up-regulation of SOX9 expression in other model systems, the molecular mechanism by which $\beta$-catenin up-regulates SOX9 has not been defined previously. Previous studies reported that several TCF4-binding motifs are located at long-range upstream and downstream enhancers of the Sox 9 promoter (Bagheri-Fam et al. 2006). The sequence, position, and orientation of TCF4binding motifs are conserved between human and mouse Sox9 promoters, suggesting that these elements are important for Sox 9 transcription (Kanai and Koopman 1999). Careful examination of a set of human ADM lesions revealed coexpression of ATDC, $\beta$-catenin, and SOX9, suggesting that these signaling relationships are preserved in human pancreata. Mechanistically, we showed that ATDC's ability to increase SOX9 was dependent on $\beta$-catenin signaling and binding of TCF 4 to SOX9 regulatory elements in human PDA cells. This hypothesis is supported by our observation that a positive correlation exists between ATDC and SOX9 expression levels in human PDA and may extend to other malignancies.

A number of studies have defined key developmental and duct cell regulatory genes such as PDX1, nestin, and SOX9, which are re-expressed in the pancreas during ADM formation (Jensen et al. 2005; Pin et al. 2015). SOX9 is expressed in pancreatic progenitor cells and becomes restricted to ductal cells in the adult organ (Seymour et al. 2007). Kopp et al. (2012) showed that deletion of SOX9 from acinar cells expressing oncogenic KRAS resulted in a complete blockage of PanIN formation, while overexpression of SOX9 in the context of oncogenic KRAS enhanced ADM/PanIN development. In a separate study, ADM initiated by NFATc1/4 in response to EGF signaling in acinar cells also required SOX9, further implicating SOX9 as a key regulator of ADM formation (Hessmann et al. 2016).

Using a physiological 3D cell culture model of ADM, we showed that SOX9 expression was significantly up-regulated during ADM formation and was coexpressed with ATDC in ADM/PanIN lesions from KPCY mice as well as in human ADM specimens. Knockout of ATDC blocked SOX9 expression in $\mathrm{KRAS}^{\mathrm{G} 12 \mathrm{D}}$-induced $\mathrm{ADM}$ lesions in 3D cultures, while overexpression of SOX9 rescued ADM formation in an ATDC-null background, demonstrating that ATDC's ability to promote progression from ADM to PanIN lesions required SOX9. Of note, our data show that expression of ATDC was not required for cerulein-induced ADM formation, and Sox9 expression was detectable before induction of ATDC. Therefore, because human ADM lesions were positive for both ATDC and SOX9, it is possible that the ADM lesions described in this study may represent an intermediate step along the ADM-to-PanIn progression, perhaps as a consequence of long-standing inflammation.

Of interest, we observed a more profound effect of loss of ATDC in vivo than in the in vitro setting. One possible explanation for this observation might be that in 3D culture conditions, the presence of polymerized collagen I at levels not seen in a healthy pancreas might partially complement the lack of ATDC, possibly downstream from SOX9. Another intriguing possibility is that ATDC may play a role in modulating the immune system in vivo that is not contributory in the in vitro setting. Two recent studies reported that loss of ATDC enhances the innate immune response against viral and bacterial infections. In particular, ATDC was found to mediate ubiquitination and proteolytic degradation of NEMO (Xing et al. 2016) and stimulator of interferon genes (STING) (Xing et al. 2017; Li et al. 2018) proteins in alveolar macrophages and airway epithelial cells, respectively. As a consequence, loss of ATDC results in increased levels of NEMO and STING proteins, which in turn induce the type I interferon pathway, the release of proinflammatory cytokines, and the activation of the immune response (Barber 2015; Ng et al. 2018). Recent studies have shown that the STING pathway is essential for radiation-induced and spontaneous natural antitumor T-cell responses (Deng et al. 2014; Woo et al. 2014; Ho et al. 2016). Because, the STING protein has been detected in human and murine PDAs (Baird et al. 2016), future experiments are needed to determine whether ATDC might have an immune regulatory role during pancreatic cancer initiation and progression.

In summary (Supplemental Fig. S7C), we provide the first evidence of a critical role of ATDC in oncogenic KRAS-induced reprogramming of the pancreatic epithelia en route to tumorigenesis. In this context, ATDC activates $\beta$-catenin signaling, which results in transcriptional activation of SOX9 via binding of TCF4 to key binding motifs in the SOX9 promoter. The ATDC/ $\beta$-catenin/ SOX9 signaling axis is critical for the development of neoplastic precursors in the pancreas, which do not form in the absence of ATDC, suggesting that there may be a benefit in targeting the pathway in high-risk patients to decrease the development of PDA.

Materials and methods

Mouse strains

All animal studies were approved by the Institutional Animal Care and Use Committee at the University of Michigan. For the generation of conditional ATDC knockout mice, C57BL/6N mouse embryonic stem cell clones harboring Atdc alleles in which exons 2-4 of Atdc are flanked by two Loxp sites were purchased from the European Mouse Mutant Cell Repository. Embryonic stem cell clones carrying Atdc-floxed alleles were injected into blastocysts of BALB/c donor mice at the University of Michigan Transgenic Animal Model Core. Chimeras were bred with $\mathrm{C} 57 \mathrm{BL} / 6 \mathrm{~N}$ animals, and successful germline transmission was indicated by black F1 offspring with the targeted allele. Mice carrying Atdc-floxed alleles were intercrossed to achieve homozygosity $\left(A t d c^{f l / f 1}\right)$. Deletion of $A t d c$ in the pancreas was achieved by mating $A t d c^{f 1 / f 1}$ mice with Pdx1-Cre mice (C) to generate $P d \times 1^{\text {Cre }} ; A t d c^{-/-}\left(\mathrm{CA}^{-/-}\right)$mice. KPCY mice were interbred with $A t d c^{f 1 / f 1}$ mice to produce $\mathrm{KPCYA}^{-/+}$and $\mathrm{KPCYA}^{-/+}$ mice.

Histologic, immunohistochemical, and immunofluorescence analysis

Tissues were fixed in $10 \%$ neutral buffered formalin and embedded in paraffin, and $5-\mu \mathrm{m}$ sections were prepared. Routine H\&E, 
immunohistochemical, and immunofluorescence staining was performed as described previously (Wang et al. 2015). For a list of the antibodies used, see Supplemental Table 6. Images were taken with a Panoramic DESK 3DHistech slide scanner (Caliper Life Sciences) and Nikon Al Eclipse Ti confocal microscope. Cell nuclei were counterstained with DAPI (Life Technologies). Histopathological analysis and quantification and grading of PanIN lesions were performed by an experienced pancreatic pathologist in a blinded manner as described previously (Wang et al. 2015). Quantification of images was performed using the HALO 2.0 image analysis software platform (Indica Labs).

\section{Isolation of primary pancreatic acinar cells and $3 D$ cultures}

Isolation of primary pancreatic acinar cells and establishment of 3D explant cultures was performed as described previously (Liou et al. 2015). Acinar cells were infected with adenoviral or lentiviral constructs of interest (see Supplemental Table 7) and incubated for 3-5 $\mathrm{h}$ before being embedded in the collagen/Waymouth medium mixture. On days 1, 3, and 5, the number of duct-like structures was counted and quantitated in a blinded manner. The area of ducts was measured using ImageJ software and StatsDirect (StatsDirect Ltd; http://www.statsdirect.com) to obtain a distribution curve. Quantification of ductal structures was performed by counting at least four individual fields at $10 \times$ magnification in triplicate.

\section{Quantitative RT-PCR ( $q R T$-PCR)}

qRT-PCR was processed as described previously (Wang et al. 2015). RNA was extracted from pancreatic tissues or isolated acinar cells of KPCY or $\mathrm{KPCYA}^{-/-}$mice using the RNeasy mini or micro kits (Qiagen) according to the manufacturer's instructions and eluted in 40 or $15 \mathrm{~mL}$ of RNase-free $\mathrm{H}_{2} \mathrm{O}$. cDNA was generated from RNA using high-capacity cDNA reverse transcription kit (Life Technologies). qPCR was performed using Applied Biosystems ViiA 7 real-time PCR system according to the manufacturer's instructions using TaqMan probes (Applied Biosystems) and the following PCR protocol: denaturation for $2 \mathrm{~min}$ at $95^{\circ} \mathrm{C}$ followed by 40 cycles for $15 \mathrm{sec}$ at $95^{\circ} \mathrm{C}, 1 \mathrm{~min}$ at $60^{\circ} \mathrm{C}$, and $15 \mathrm{sec}$ at $72^{\circ} \mathrm{C}$. To verify the specificity of the PCR amplification products, melting curve analysis was performed. mRNA levels were normalized to GAPDH mRNA levels.

\section{Flow cytometry and cell sorting}

Blood samples $(0.5-1 \mathrm{~mL})$ from KPCY or $\mathrm{KPCYA}^{-/-}$mice were treated with red blood cell lysis reagent (Thermo Fisher Scientific, Inc.). $\mathrm{YFP}^{+} \mathrm{CPCs}$ were counted by flow cytometric analysis (FACSCalibur, BD) as described previously (Rhim et al. 2012).

\section{Immunoblot analysis}

Western blot analysis and coimmunoprecipitation experiments were performed as described previously (Wang et al. 2009). The primary antibodies used and their dilutions are listed in Supplemental Table 5. After incubation with IRDye secondary antibodies (LI-COR Biotechnology) suitable for multicolor detection, protein bands were visualized using an Odyssey CLx imager (LI-COR Biotechnology). After analysis, blots were stripped, washed, and reprobed with a $\beta$-actin antibody (Sigma), which served as a loading control. Protein expression was quantified using Odyssey Imaging Systems software.

\section{RAS activity assays}

RAS activity was assessed using Raf-1-RBD (Ras-binding domain) pull-down assays. In brief, freshly isolated acinar cells from 1.5-mo-old KCY or $\mathrm{KCYA}^{-/-}$mice were lysed with buffer A (50 mM Tris/HCl at $\mathrm{pH} 7.4,1 \%$ Triton X-100, $150 \mathrm{mM} \mathrm{NaCl}$, $5 \mathrm{mM}$ EDTA) plus a protease inhibitor cocktail (Sigma-Aldrich). Clarified cellular lysates were incubated with $20 \mathrm{mg}$ of GSTRaf-1- RBD (amino acids 1-149) for $90 \mathrm{~min}$ at $4^{\circ} \mathrm{C}$ followed by three washes with buffer A. Samples were run on SDS-PAGE, transferred to nitrocellulose membranes, and analyzed for Ras (anti-Ras antibody) and $\mathrm{Kras}^{\mathrm{G} 12 \mathrm{D}}$ (anti-Kras ${ }^{\mathrm{G} 12 \mathrm{D}}$ antibody). Input was controlled by staining of lysates for total anti-Ras or antiKras ${ }^{\mathrm{G} 12 \mathrm{D}}$ and $\beta$-actin.

\section{In vitro ChIP assays}

ChIP assays were performed in human PDA cell lines expressing control or $\beta$-catenin shRNA using the SimpleChIP ChIP kit (Cell Signaling) according to the manufacturer's instructions. Briefly, $4 \times 10^{7}$ PDA cells were treated with $1 \%$ formaldehyde to cross-link histones to DNA. The cross-linking was stopped by treating the samples with stop buffer for $5 \mathrm{~min}$. The chromatin was extracted and fragmented by incubation with micrococcal nuclease for $20 \mathrm{~min}$ at $37^{\circ} \mathrm{C}$ to digest DNA to a length of $\sim 150$ $900 \mathrm{bp}$. For each immunoprecipitation, $500 \mu \mathrm{L}$ of the diluted chromatin was transferred to microcentrifuge tubes. ChIP-grade TCF4 antibody (C9B9; Cell Signaling) was added, and the sample was incubated overnight at $4{ }^{\circ} \mathrm{C}$ with rotation. Nonimmune normal rabbit IgG (Cell Signaling, 2729) was used as a negative control. ChIP-grade protein G magnetic beads (Cell Signaling, 9006) were added to the lysate to isolate the antibody-bound complexes. Pellet protein G magnetic beads were pulled down and washed, and chromatin was eluted. Immunoprecipitated DNA $(25 \mu \mathrm{g})$ was purified using a DNA purification spin column provided in the kit. TCF4-binding motifs on the Sox9 promoter region were analyzed and identified by real-time qPCR using specially designed primers. The signals were normalized to the input, and the signal was obtained with the nonimmune normal rabbit IgG immunoprecipitation. Data are expressed as the mean values \pm SE of three independent experiments. The primers used are listed in Supplemental Table 4.

\section{TCGA gene expression analysis}

To assess the relationship between ATDC and SOX9 gene expression in human cancer samples, we downloaded the batch effect normalized RNA sequencing gene expression data generated by the TCGA Pan-Cancer Atlas that covers the 33 most prevalent forms of cancer. We used the 9675 primary tumor samples available in the data set. To estimate the measure of association between genes and its significance, the Pearson product moment correlation coefficient was calculated within each cohort.

\section{Orthotopic xenografts}

C57BL/6 mice were obtained from The Charles River Laboratories. For orthotopic implantation of PDECs, mice were anesthetized using a ketamine/xylazine cocktail, and a small $(7-\mathrm{mm})$ left abdominal side incision was made. PDECs $\left(1 \times 10^{6}\right.$ cells per mouse) were suspended in Matrigel diluted 1:1 with cold PBS (total volume of $50 \mathrm{~mL}$ ) and injected into the tail region of the pancreas using a 26-gauge needle. A successful injection was verified by the appearance of a fluid bubble without intraperitoneal leakage. The abdominal wall was closed with absorbable sutures, and the skin was closed with wound clips. Mice were sacrificed at the 
indicated time points, and grafts were measured and processed for histology. All animal care and procedures were approved by the Institutional Animal Care and Use Committee at New York University School of Medicine.

\section{Assessment of primary and metastatic disease burden}

Complete necropsies were performed on all animals in the study. Gross pathology and histopathology of internal organs were analyzed for macroscopic and microscopic disease as described previously (Wang et al. 2015).

\section{Statistical analysis}

Unless indicated otherwise, the significance of data was determined by the two-tailed Student's $t$-test. A value of $P<0.05$ was considered statistically significant. Fisher's exact $t$-test was performed to compare disease burden in KCY versus $\mathrm{KCYA}^{-/-}$ mice. Statistical analyses were performed using GraphPad Prism 7.0 software.

\section{Acknowledgments}

We thank members of the Simeone laboratory for technical assistance and helpful discussions. We appreciate the help of the Howard Crawford laboratory and Dafna Bar-Sagi laboratory in sharing technical advice in establishing the acinar $3 \mathrm{D}$ cultures and in use of the K-RAS ${ }^{\mathrm{G} 12 \mathrm{D}}$ PDECs. This work was supported by funding from the National Cancer Institute (grants 2R01CA131045 and 1R01CA174836 to D.M.S.) and the Sky Foundation (to D.M.S. and H.C.C.)

Author contributions: L.W., H.Y., A.Z., M.L., C.H.H., C.J.H., I.D., H.C.C., and D.M.S. devised and performed the experiments, analyzed the results, and prepared the manuscript. P.L.P., E.V.A., V.P., A.D.R., D.B.-S., M.P.d.M., and D.D. provided reagents and expertise, helped prepare the manuscript, and provided feedback.

\section{References}

Ahmad I, Patel R, Liu Y, Singh LB, Taketo MM, Wu XR, Leung HY, Sansom OJ. 2011. Ras mutation cooperates with $\beta$-catenin activation to drive bladder tumourigenesis. Cell Death Dis 2: e124. doi:10.1038/cddis.2011.7

Ardito CM, Grüner BM, Takeuchi KK, Lubeseder-Martellato C, Teichmann N, Mazur PK, Delgiorno KE, Carpenter ES, Halbrook CJ, Hall JC, et al. 2012. EGF receptor is required for KRAS-induced pancreatic tumorigenesis. Cancer Cell 22: 304-317. doi:10.1016/j.ccr.2012.07.024

Baer R, Cintas C, Dufresne M, Cassant-Sourdy S, Schonhuber N, Planque L, Lulka H, Couderc B, Bousquet C, Garmy-Susini B, et al. 2014. Pancreatic cell plasticity and cancer initiation induced by oncogenic Kras is completely dependent on wildtype PI 3-kinase p110a. Genes Dev 28: 2621-2635. doi:10 $.1101 / \operatorname{gad} .249409 .114$

Bagheri-Fam S, Barrionuevo F, Dohrmann U, Günther T, Schüle R, Kemler R, Mallo M, Kanzler B, Scherer G. 2006. Long-range upstream and downstream enhancers control distinct subsets of the complex spatiotemporal Sox 9 expression pattern. Dev Biol 291: 382-397. doi:10.1016/j.ydbio.2005.11.013

Baird JR, Friedman D, Cottam B, Dubensky TW, Kanne DB, Bambina S, Bahjat K, Crittenden MR, Gough MJ. 2016. Radiotherapy combined with novel STING-targeting oligonucleotides results in regression of established tumors. Cancer Research 76: 50-61. doi:10.1158/0008-5472.CAN-14-3619

Barber GN. 2015. STING: infection, inflammation and cancer. Nat Rev Immunol 15: 760-770. doi:10.1038/nri3921

Blache P, van de Wetering M, Duluc I, Domon C, Berta P, Freund JN, Clevers H, Jay P. 2004. SOX9 is an intestine crypt transcription factor, is regulated by the Wnt pathway, and represses the CDX2 and MUC2 genes. J Cell Biol 166: 37-47. doi:10 $.1083 /$ jcb. 200311021

The Cancer Genome Atlas Research Network. 2017. Integrated genomic characterization of pancreatic ductal adenocarcinoma. Cancer Cell 32: 185-203.e13.

Carrière C, Young AL, Gunn JR, Longnecker DS, Korc M. 2009. Acute pancreatitis markedly accelerates pancreatic cancer progression in mice expressing oncogenic Kras. Biochem Biophys Res Commun 382: 561-565. doi:10.1016/j.bbrc.2009.03 .068

Chen NM, Singh G, Koenig A, Liou GY, Storz P, Zhang JS, Regul L, Nagarajan S, Kuhnemuth B, Johnsen SA, et al. 2015. NFATc1 links EGFR signaling to induction of Sox9 transcription and acinar-ductal transdifferentiation in the pancreas. Gastroenterology 148: 1024-1034.e9. doi:10.1053/j.gastro .2015 .01 .033

Collins MA, Bednar F, Zhang Y, Brisset JC, Galbán S, Galbán CJ, Rakshit S, Flannagan KS, Adsay NV, Pasca di Magliano M. 2012. Oncogenic Kras is required for both the initiation and maintenance of pancreatic cancer in mice. J Clin Invest 122: 639-653. doi:10.1172/JCI59227

Corcoran RB, Contino G, Deshpande V, Tzatsos A, Conrad C, Benes $\mathrm{CH}$, Levy DE, Settleman J, Engelman JA, Bardeesy N. 2011. STAT3 plays a critical role in KRAS-induced pancreatic tumorigenesis. Cancer Res 71: 5020-5029. doi:10.1158/00085472.CAN-11-0908

Daniluk J, Liu Y, Deng D, Chu J, Huang H, Gaiser S, Cruz-Monserrate Z, Wang H, Ji B, Logsdon CD. 2012. An NF-кB pathway-mediated positive feedback loop amplifies Ras activity to pathological levels in mice. J Clin Invest 122: 1519-1528. doi:10.1172/JCI59743

De La OJ, Emerson LL, Goodman JL, Froebe SC, Illum BE, Curtis AB, Murtaugh LC. 2008. Notch and Kras reprogram pancreatic acinar cells to ductal intraepithelial neoplasia. Proc Natl Acad Sci 105: 18907-18912. doi:10.1073/pnas.0810111105

Deng L, Liang H, Xu M, Yang X, Burnette B, Arina A, Li XD, Mauceri H, Beckett M, Darga T, et al. 2014. STING-dependent cytosolic DNA sensing promotes radiation-induced type I interferon-dependent antitumor immunity in immunogenic tumors. Immunity 41: 843-852. doi:10.1016/j.immuni.2014 .10 .019

The ENCODE Project Consortium. 2012. An integrated encyclopedia of DNA elements in the human genome. Nature 489: 57-74. doi:10.1038/nature11247

Garcia MN, Grasso D, Lopez-Millan MB, Hamidi T, Loncle C, Tomasini R, Lomberk G, Porteu F, Urrutia R, Iovanna JL. 2014. IER3 supports KRASG12D-dependent pancreatic cancer development by sustaining ERK1/2 phosphorylation. J Clin Invest 124: 4709-4722. doi:10.1172/JCI76037

Gruber R, Panayiotou R, Nye E, Spencer-Dene B, Stamp G, Behrens A. 2016. YAP1 and TAZ control pancreatic cancer initiation in mice by direct up-regulation of JAK-STAT3 signaling. Gastroenterology 151: 526-539. doi:10.1053/j.gastro.2016.05 .006

Guerra C, Schuhmacher AJ, Cañamero M, Grippo PJ, Verdaguer L, Pérez-Gallego L, Dubus P, Sandgren EP, Barbacid M. 2007. Chronic pancreatitis is essential for induction of pancreatic 
ductal adenocarcinoma by K-Ras oncogenes in adult mice. Cancer Cell 11: 291-302. doi:10.1016/j.ccr.2007.01.012

Habbe N, Shi G, Meguid RA, Fendrich V, Esni F, Chen H, Feldmann G, Stoffers DA, Konieczny SF, Leach SD, et al. 2008. Spontaneous induction of murine pancreatic intraepithelial neoplasia (mPanIN) by acinar cell targeting of oncogenic Kras in adult mice. Proc Natl Acad Sci 105: 18913-18918. doi:10.1073/pnas.0810097105

Harris TM, Du P, Kawachi N, Belbin TJ, Wang Y, Schlecht NF, Ow TJ, Keller CE, Childs GJ, Smith RV, et al. 2015. Proteomic analysis of oral cavity squamous cell carcinoma specimens identifies patient outcome-associated proteins. Arch Pathol Lab Med 139: 494-507. doi:10.5858/arpa.2014-0131-OA

Hatakeyama S. 2016. Early evidence for the role of TRIM29 in multiple cancer models. Expert Opin Ther Targets 20: 767770. doi:10.1517/14728222.2016.1148687

He G, Yu G-Y, Temkin V, Ogata H, Kuntzen C, Sakurai T, Sieghart W, Peck-Radosavljevic M, Leffert HL, Karin M. 2010. Hepatocyte IKK $\beta / \mathrm{NF}-\kappa \mathrm{B}$ inhibits tumor promotion and progression by preventing oxidative stress-driven STAT3 activation. Cancer Cell 17: 286-297. doi:10.1016/j.ccr.2009.12.048

He P, Yang JW, Yang VW, Bialkowska AB. 2018. Krüppel-like factor 5 , increased in pancreatic ductal adenocarcinoma, promotes proliferation, acinar-to-ductal metaplasia, pancreatic intraepithelial neoplasia, and tumor growth in mice. Gastroenterology 154: 1494-1508.e13. doi:10.1053/j.gastro.2017.12 .005

Hessmann E, Zhang JS, Chen NM, Hasselluhn M, Liou GY, Storz P, Ellenrieder V, Billadeau DD, Koenig A. 2016. NFATc4 regulates Sox9 gene expression in acinar cell plasticity and pancreatic cancer initiation. Stem Cells Int 2016: 5272498. doi:10.1155/2016/5272498

Hingorani SR, Petricoin EF, Maitra A, Rajapakse V, King C, Jacobetz MA, Ross S, Conrads TP, Veenstra TD, Hitt BA, et al. 2003. Preinvasive and invasive ductal pancreatic cancer and its early detection in the mouse. Cancer Cell 4: 437-450. doi:10.1016/S1535-6108(03)00309-X

Ho SS, Zhang WY, Tan NY, Khatoo M, Suter MA, Tripathi S, Cheung FS, Lim WK, Tan PH, Ngeow J, et al. 2016. The DNA structure-specific endonuclease MUS81 mediates DNA sensor STING-dependent host rejection of prostate cancer cells. Immunity 44: 1177-1189. doi:10.1016/j.immuni .2016.04.010

Hosoi Y, Kapp LN. 1994. Expression of a candidate ataxia-telangiectasia group D gene in cultured fibroblast cell lines and human tissues. Int J Radiat Biol 66: S71-S76.

Hruban RH, Maitra A, Goggins M. 2008. Update on pancreatic intraepithelial neoplasia. Int I Clin Exp Pathol 1: 306-316.

Jensen JN, Cameron E, Garay MV, Starkey TW, Gianani R, Jensen J. 2005. Recapitulation of elements of embryonic development in adult mouse pancreatic regeneration. Gastroenterology 128: 728-741. doi:10.1053/j.gastro.2004.12.008

Jiang Z, Zhou C, Cheng L, Yan B, Chen K, Chen X, Zong L, Lei J, Duan $\mathrm{W}, \mathrm{Xu} \mathrm{Q}$, et al. 2018. Inhibiting YAP expression suppresses pancreatic cancer progression by disrupting tumorstromal interactions. I Exp Clin Cancer Res 37: 69. doi:10 $.1186 / \mathrm{s} 13046-018-0740-4$

Kanai Y, Koopman P. 1999. Structural and functional characterization of the mouse Sox9 promoter: implications for campomelic dysplasia. Hum Mol Genet 8: 691-696. doi:10.1093/ $\mathrm{hmg} / 8.4 .691$

Kapp LN, Painter RB, Yu LC, van Loon N, Richard CW III, James MR, Cox DR, Murnane JP. 1992. Cloning of a candidate gene for ataxia-telangiectasia group D. Am J Hum Genet 51: 45-54.
Kopp JL, von Figura G, Mayes E, Liu FF, Dubois CL, Morris J, Pan FC, Akiyama H, Wright CV, Jensen $\mathrm{K}$, et al. 2012. Identification of Sox9-dependent acinar-to-ductal reprogramming as the principal mechanism for initiation of pancreatic ductal adenocarcinoma. Cancer Cell 22: 737-750. doi:10.1016/j.ccr .2012 .10 .025

Krah NM, De La OJ, Swift GH, Hoang CQ, Willet SG, Chen Pan F, Cash GM, Bronner MP, Wright CV, MacDonald RJ, et al. 2015. The acinar differentiation determinant PTF1A inhibits initiation of pancreatic ductal adenocarcinoma. Elife 4: e07125. doi:10.7554/eLife.07125

Kugel S, Sebastian C, Fitamant J, Ross KN, Saha SK, Jain E, Gladden A, Arora KS, Kato Y, Rivera MN, et al. 2016. SIRT6 suppresses pancreatic cancer through control of Lin28b. Cell 165: 1401-1415. doi:10.1016/j.cell.2016.04.033

Lai W, Zhao J, Zhang C, Cui D, Lin J, He Y, Zheng H, Wu X, Yang M. 2013. Upregulated ataxia-telangiectasia group D complementing gene correlates with poor prognosis in patients with esophageal squamous cell carcinoma. Dis Esophagus 26: 817-822. doi:10.1111/j.1442-2050.2012.01400.x

Li Q, Lin L, Tong Y, Liu Y, Mou J, Wang X, Wang X, Gong Y, Zhao $\mathrm{Y}$, Liu Y, et al. 2018. TRIM29 negatively controls antiviral immune response through targeting STING for degradation. Cell Discov 4: 13. doi:10.1038/s41421-018-0010-9

Ling J, Kang Y, Zhao R, Xia Q, Lee D-F, Chang Z, Li J, Peng B, Fleming JB, Wang H, et al. 2012. KrasG12D-induced IKK2/ $\beta /$ NF- $\kappa \mathrm{B}$ activation by IL-1 $\alpha$ and $\mathrm{p} 62$ feedforward loops is required for development of pancreatic ductal adenocarcinoma. Cancer cell 21: 105-120. doi:10.1016/j.ccr.2011.12.006

Liou GY, Döppler H, Braun UB, Panayiotou R, Scotti Buzhardt M, Radisky DC, Crawford HC, Fields AP, Murray NR, Wang QJ, et al. 2015. Protein kinase D1 drives pancreatic acinar cell reprogramming and progression to intraepithelial neoplasia. Nat Commun 6: 6200. doi: $10.1038 /$ ncomms 7200

Maitra A, Hruban RH. 2008. Pancreatic cancer. Annu Rev Pathol 3: 157-188. doi:10.1146/annurev.pathmechdis.3.121806 .154305

Mazur PK, Reynoird N, Khatri P, Jansen PW, Wilkinson AW, Liu S, Barbash O, Van Aller GS, Huddleston M, Dhanak D, et al. 2014. SMYD3 links lysine methylation of MAP3K2 to Rasdriven cancer. Nature 510: 283-287. doi:10.1038/nature 13320

Ng KW, Marshall EA, Bell JC, Lam WL. 2018. cGAS-STING and cancer: dichotomous roles in tumor immunity and development. Trends Immunol 39: 44-54. doi:10.1016/j.it.2017.07 .013

Pacheco-Pinedo EC, Durham AC, Stewart KM, Goss AM, Lu MM, Demayo FJ, Morrisey EE. 2011. Wnt/ $\beta$-catenin signaling accelerates mouse lung tumorigenesis by imposing an embryonic distal progenitor phenotype on lung epithelium. J Clin Invest 121: 1935-1945. doi:10.1172/JCI44871

Pasca di Magliano M, Biankin AV, Heiser PW, Cano DA, Gutierrez PJ, Deramaudt T, Segara D, Dawson AC, Kench JG, Henshall SM, et al. 2007. Common activation of canonical Wnt signaling in pancreatic adenocarcinoma. PLoS One 2: e1155. doi:10.1371/journal.pone.0001155

Pin CL, Rukstalis JM, Johnson C, Konieczny SF. 2001. The bHLH transcription factor Mistl is required to maintain exocrine pancreas cell organization and acinar cell identity. I Cell Biol 155: 519-530. doi:10.1083/jcb. 200105060

Pin CL, Ryan JF, Mehmood R. 2015. Acinar cell reprogramming: a clinically important target in pancreatic disease. Epigenomics 7: 267-281. doi:10.2217/epi.14.83

Prévot PP, Simion A, Grimont A, Colletti M, Khalaileh A, Van den Steen G, Sempoux C, Xu X, Roelants V, Hald J, et al. 2012. Role of the ductal transcription factors HNF6 and 
Sox9 in pancreatic acinar-to-ductal metaplasia. Gut 61: 17231732. doi:10.1136/gutjnl-2011-300266

Pylayeva-Gupta Y, Lee KE, Hajdu CH, Miller G, Bar-Sagi D. 2012. Oncogenic Kras-induced GM-CSF production promotes the development of pancreatic neoplasia. Cancer Cell 21: 836847. doi:10.1016/j.ccr.2012.04.024

Rahib L, Smith BD, Aizenberg R, Rosenzweig AB, Fleshman JM, Matrisian LM. 2014. Projecting cancer incidence and deaths to 2030: the unexpected burden of thyroid, liver, and pancreas cancers in the United States. Cancer Res 74: 2913-2921. doi:10.1158/0008-5472.CAN-14-0155

Reymond A, Meroni G, Fantozzi A, Merla G, Cairo S, Luzi L, Riganelli D, Zanaria E, Messali S, Cainarca S, et al. 2001. The tripartite motif family identifies cell compartments. EMBO I 20: 2140-2151. doi:10.1093/emboj/20.9.2140

Rhim AD, Mirek ET, Aiello NM, Maitra A, Bailey JM, McAllister F, Reichert M, Beatty GL, Rustgi AK, Vonderheide RH, et al. 2012. EMT and dissemination precede pancreatic tumor formation. Cell 148: 349-361. doi:10.1016/j.cell.2011.11.025

Rozengurt E, Sinnett-Smith J, Eibl G. 2018. Yes-associated protein (YAP) in pancreatic cancer: at the epicenter of a targetable signaling network associated with patient survival. Signal Transduct Target Ther 3: 11. doi:10.1038/s41392-017-0005-2

Seifert L, Werba G, Tiwari S, Giao Ly NN, Alothman S, Alqunaibit D, Avanzi A, Barilla R, Daley D, Greco SH, et al. 2016. The necrosome promotes pancreatic oncogenesis via CXCL1 and Mincle-induced immune suppression. Nature 532: 245-249. doi:10.1038/nature 17403

Seymour PA, Freude KK, Tran MN, Mayes EE, Jensen J, Kist R, Scherer G, Sander M. 2007. SOX9 is required for maintenance of the pancreatic progenitor cell pool. Proc Natl Acad Sci 104: 1865-1870. doi:10.1073/pnas.0609217104

Shen J, Ha DP, Zhu G, Rangel DF, Kobielak A, Gill PS, Groshen S, Dubeau L, Lee AS. 2017. GRP78 haploinsufficiency suppresses acinar-to-ductal metaplasia, signaling, and mutant Krasdriven pancreatic tumorigenesis in mice. Proc Natl Acad Sci 114: E4020-E4029. doi:10.1073/pnas.1616060114

Strobel O, Dor Y, Alsina J, Stirman A, Lauwers G, Trainor A, Castillo CF, Warshaw AL, Thayer SP. 2007. In vivo lineage tracing defines the role of acinar-to-ductal transdifferentiation in inflammatory ductal metaplasia. Gastroenterology 133: 19992009. doi:10.1053/j.gastro.2007.09.009

Wang L, Heidt DG, Lee CJ, Yang H, Logsdon CD, Zhang L, Fearon ER, Ljungman M, Simeone DM. 2009. Oncogenic function of ATDC in pancreatic cancer through Wnt pathway activation and $\beta$-catenin stabilization. Cancer Cell 15: 207-219. doi:10 $.1016 /$ j.ccr.2009.01.018
Wang L, Yang H, Abel EV, Ney GM, Palmbos PL, Bednar F, Zhang Y, Leflein J, Waghray M, Owens S, et al. 2015. ATDC induces an invasive switch in KRAS-induced pancreatic tumorigenesis. Genes Dev 29: 171-183. doi:10.1101/gad.253591.114

Wei D, Wang L, Yan Y, Jia Z, Gagea M, Li Z, Zuo X, Kong X, Huang S, Xie K. 2016. KLF4 is essential for induction of cellular identity change and acinar-to-ductal reprogramming during early pancreatic carcinogenesis. Cancer Cell 29: 324 338. doi:10.1016/j.ccell.2016.02.005

Whittle MC, Izeradjene K, Rani PG, Feng L, Carlson MA, DelGiorno KE, Wood LD, Goggins M, Hruban RH, Chang AE, et al. 2015. RUNX3 controls a metastatic switch in pancreatic ductal adenocarcinoma. Cell 161: 1345-1360. doi:10.1016/j .cell.2015.04.048

Woo SR, Fuertes MB, Corrales L, Spranger S, Furdyna MJ, Leung MY, Duggan R, Wang Y, Barber GN, Fitzgerald KA, et al. 2014. STING-dependent cytosolic DNA sensing mediates innate immune recognition of immunogenic tumors. Immunity 41: 830-842. doi:10.1016/j.immuni.2014.10.017

Xing J, Weng L, Yuan B, Wang Z, Jia L, Jin R, Lu H, Li XC, Liu Y-J, Zhang Z. 2016. Identification of a role for TRIM29 in the control of innate immunity in the respiratory tract. Nat Immunol 17: 1373-1380. doi:10.1038/ni.3580

Xing J, Zhang A, Zhang H, Wang J, Li XC, Zeng M-S, Zhang Z. 2017. TRIM29 promotes DNA virus infections by inhibiting innate immune response. Nat Commun 8: 945-945. doi:10 .1038/s41467-017-00101-w

Zhang Y, Morris J, Yan W, Schofield HK, Gurney A, Simeone DM, Millar SE, Hoey T, Hebrok M, Pasca di Magliano M. 2013. Canonical wnt signaling is required for pancreatic carcinogenesis. Cancer Res 73: 4909-4922. doi:10.1158/0008-5472.CAN12-4384

Zhang Y, Yan W, Mathew E, Bednar F, Wan S, Collins MA, Evans RA, Welling TH, Vonderheide RH, di Magliano MP. 2014. CD4+ T lymphocyte ablation prevents pancreatic carcinogenesis in mice. Cancer Immunol Res 2: 423-435. doi:10.1158/ 2326-6066.CIR-14-0016-T

Zheng X, Carstens JL, Kim J, Scheible M, Kaye J, Sugimoto H, Wu CC, LeBleu VS, Kalluri R. 2015. Epithelial-to-mesenchymal transition is dispensable for metastasis but induces chemoresistance in pancreatic cancer. Nature 527: 525-530. doi:10 $.1038 /$ nature 16064

Zhu L, Shi G, Schmidt CM, Hruban RH, Konieczny SF. 2007. Acinar cells contribute to the molecular heterogeneity of pancreatic intraepithelial neoplasia. Am J Pathol 171: 263-273. doi:10.2353/ajpath.2007.061176 


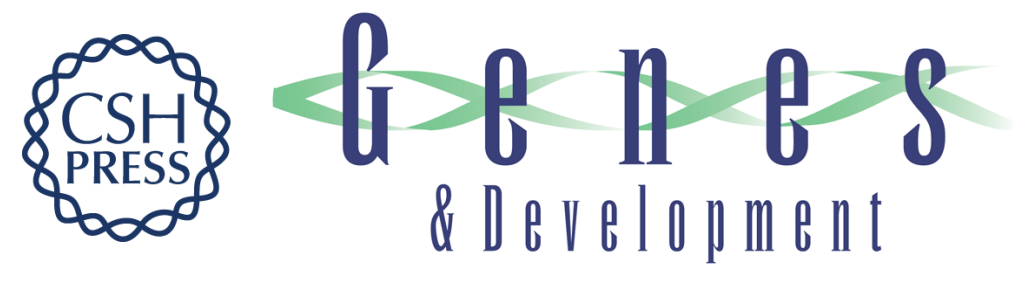

\section{ATDC is required for the initiation of KRAS-induced pancreatic tumorigenesis}

Lidong Wang, Huibin Yang, Andrea Zamperone, et al.

Genes Dev. 2019, 33: originally published online May 2, 2019

Access the most recent version at doi:10.1101/gad.323303.118

\section{Supplemental http://genesdev.cshlp.org/content/suppl/2019/04/25/gad.323303.118.DC1 Material}

References This article cites 68 articles, 15 of which can be accessed free at: http://genesdev.cshlp.org/content/33/11-12/641.full.html\#ref-list-1

Creative This article is distributed exclusively by Cold Spring Harbor Laboratory Press for the first Commons six months after the full-issue publication date (see

License http://genesdev.cshlp.org/site/misc/terms.xhtml). After six months, it is available under a Creative Commons License (Attribution-NonCommercial 4.0 International), as described at http://creativecommons.org/licenses/by-nc/4.0/.

Email Alerting Receive free email alerts when new articles cite this article - sign up in the box at the top Service right corner of the article or click here.

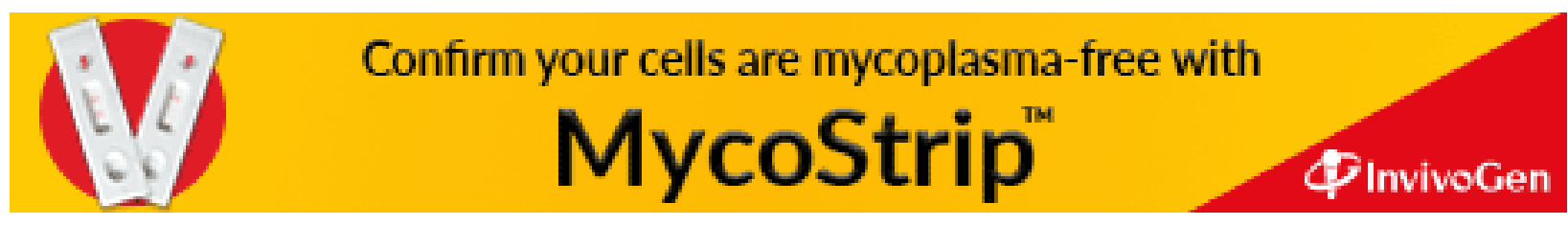

